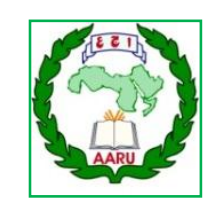

939

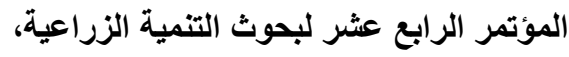

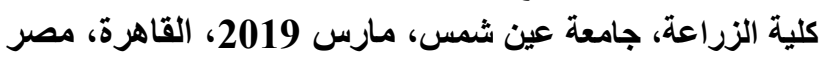
مجلا(27)، عدد (1)، عدد خاص مارس، 939- 939 952، 2019

Website: http://strategy-plan.asu.edu.eg/AUJASCI/

محددات الطلب العالمى علي البصل المجفف المصري

[86]

حاتم عبد العليم شاهين 1- محمد كامل إبراهيم ريحان 2- عبدالله محمود عبدالمقصود2 2

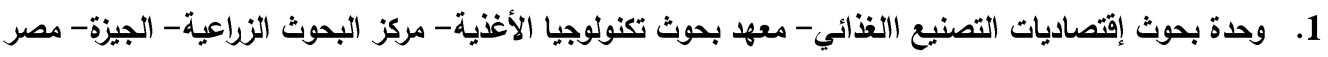

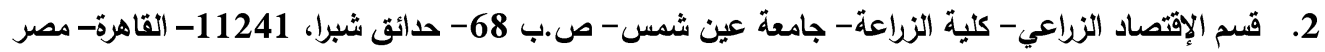

"Corresponding author: dr.hatem.shaheen11@gmail.com

Received 30 October, 2018, $\quad$ Accepted 8 November, 2018

السعرية عن الواحد (طلب غير مرن) لدولة اليابان.

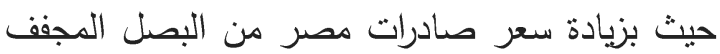
لليابان بنسبة 1\% بؤئدي إلي انخفاض كمية الصادرات بنسبة 0.51\%، بينما كانت مرونة الطلب السعرية النيان للمملكة المتحدة متكافئة حيث بزيادة سعر صانة صادرات

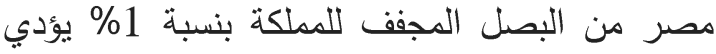
إلي انخفاض كمية الصادرات بنفس النسبة، كما تنين الصنات

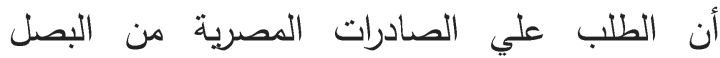
المجفف مرن بالنسبة لدول هولندا - البرازيل - بلجيكا

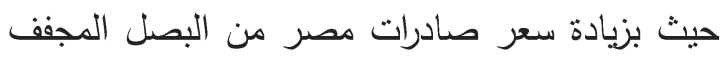
بنسبة 1\% يؤدي إلي انخفاض كمية الصادرات بنسبة

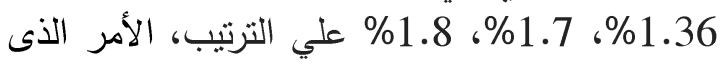
يؤدى إلى صعوبة التعامل مع تلألك الأسواق وحساسية الأبة هذه الأسواق فى التعامل معها ومحاولة زيادة الأسعار

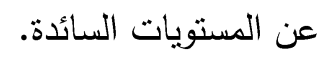

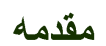

تعد صناعة التجفيف لمحاصيل الخضر وخاصة محصول البصل من أهم الصناعات الغذائية لما لها لهانيا

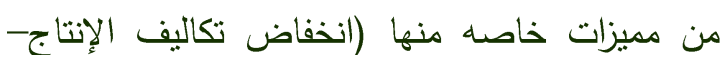
تقليل الفاقد- المحافظة على القيمة الغذائية- خفة الإنة

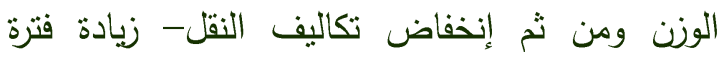

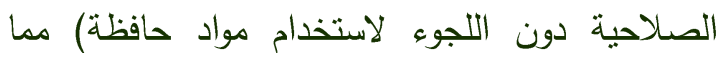
يؤدى إلى تحقيق جودة وسلامة الغذاء وفتح أبواب

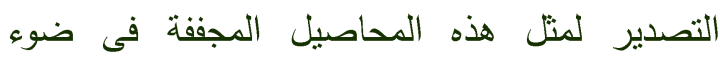
المعايير والقياسات الدولية المعمول بها.

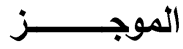

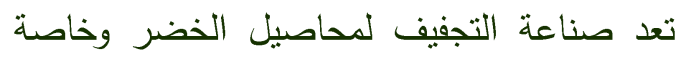

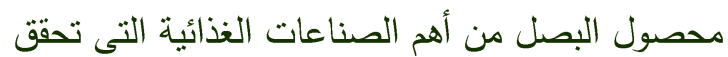
جودة وسلامة الغذاء وفتح أبواب التصدير ، وتعد ألمانيا

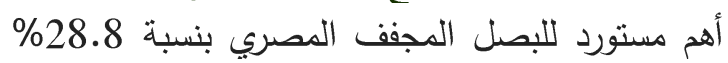

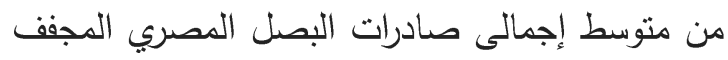
والذى ييلغ حوالى 3448 طن كمتوسط للفترة (20132017) ، يليها هولندا في قائمة اهم الدول المستوردة

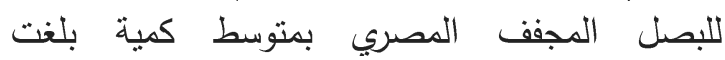
حوالى2816 طن تمثل 23.5\% من متوسط صادرات

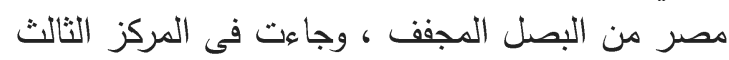

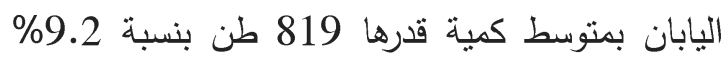

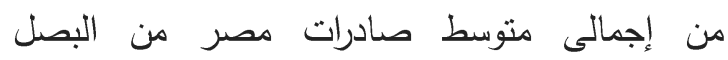
المجفف، وبعد ذلك تأتى اليونان وبلجيكا وبريطانيا والبرازيل على الترتيب.

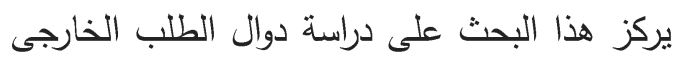

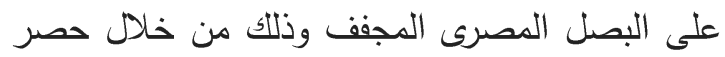

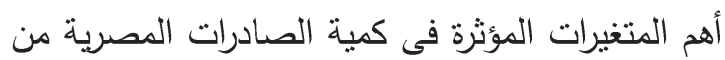

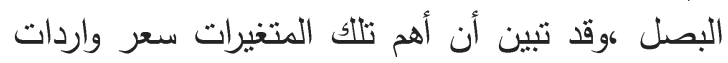
البصل المصرى المجفف فى أسواق الدول المبن المستوردة

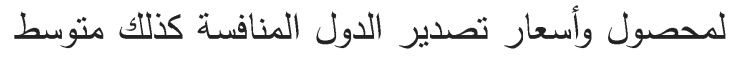
دخل الفرد بالدول المستوردة بالاضافة إلى أهمية عدد الهد الهافية

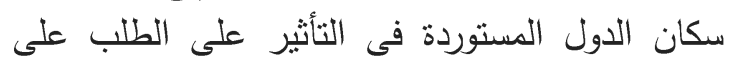
البصل المجف المبن المصرى. حيث تنين من دراسة دوال الطلب الخارجى علي الطي البصل المصرى المجف انخفاض درل درونة الطلب 


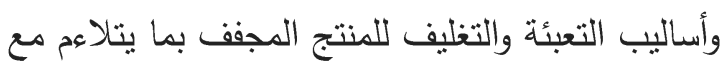

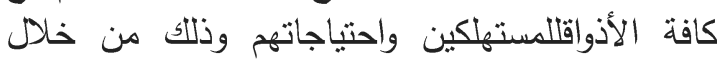
تخزين محصول البصل فيى صورة مجفية قابلة

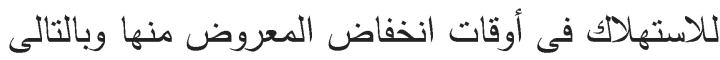

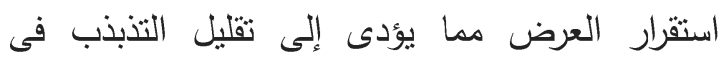

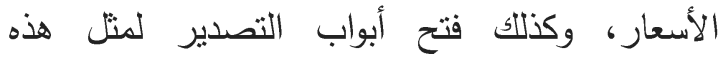

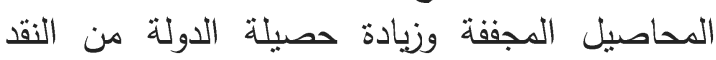
الأجنبى فى ظل ظروف عالميه جديدة أظهرت أهية

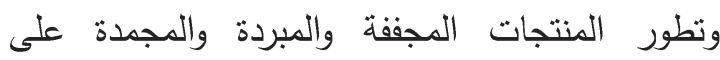
مستوى دول العالم المختلفة.

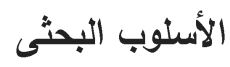

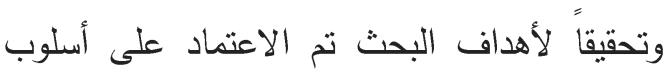

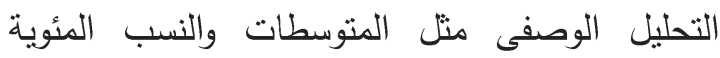
وكذلك أسلوب التحليل الكمى باستخدام بعض القابط القياسات

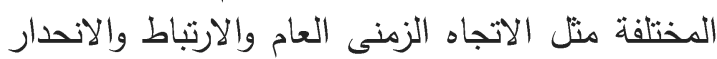

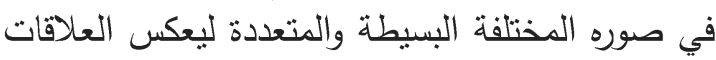

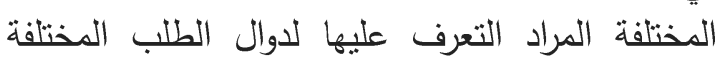
لبعض الأسواق الإستنيرادية العالمية على لإل البصل البعل المجفف المصرى. - المواق

\section{مصادر البيانات}

اعتمد البحث على البيانات الإحصائية الثانوية

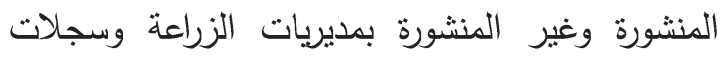

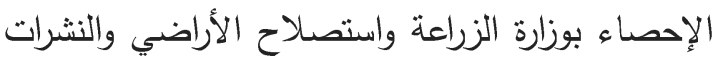
الإحصائية للتجارة الخارجية بكل من قطاع الزاعة الثئون

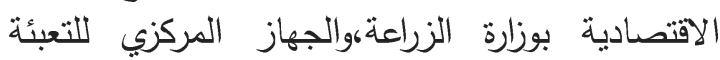

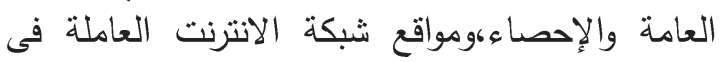

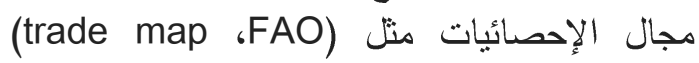
وكذلك الاستعانة بالمراجع العلمية والأبحاث والدِاتِاسات السابقة التي تتاولت موضوع الإراستمحليا ودوليا.

تطور إنتاج البصل المصري للعروات المختلفة في مصر خلال الفترة (2000-2016)

يتضدن جدول رقم (1) معادلات الاتجاه الزمني

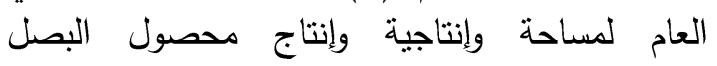
بجمهورية مصر العربية خلال الفترة (2000-2016)

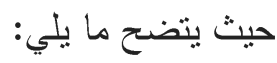

هذا بجانب التطور الواضح فى صناعة التعبئة والتغليف فى الآونة الأخيرة من حيث لئ مواد

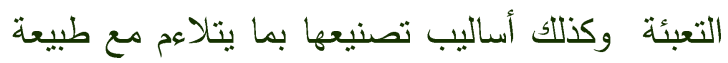

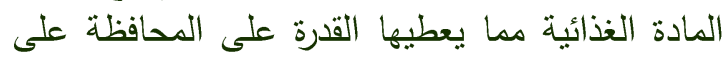

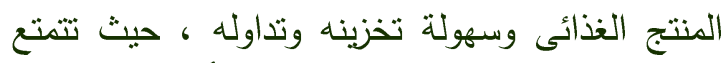

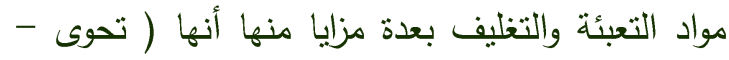

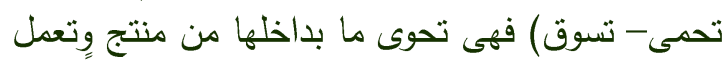

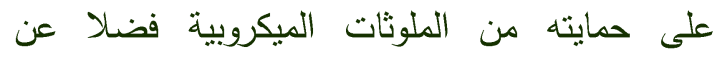

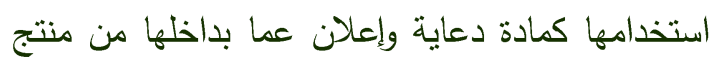
حتى تصل إلى المستهلادك.

\section{مشكلة الدراسة}

نظراً لعدم استقرار قطاع الزراعة لكونه يتأثر كثيرا

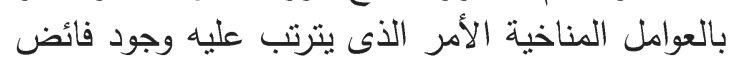

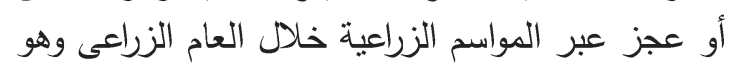

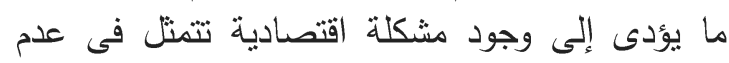

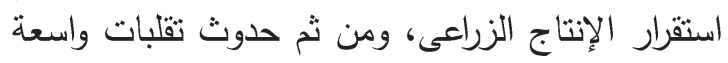

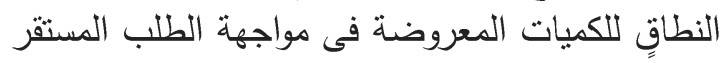

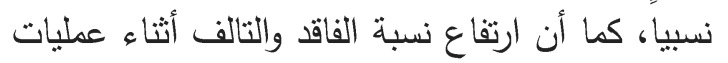

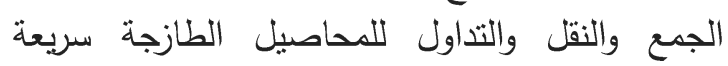

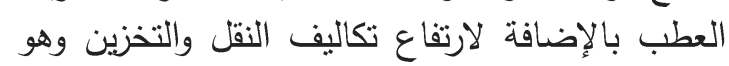

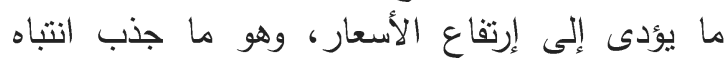

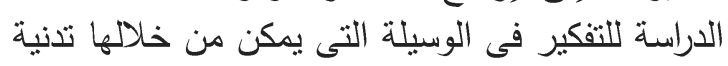

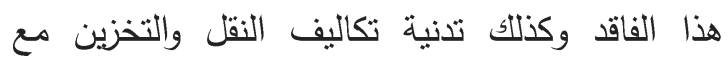

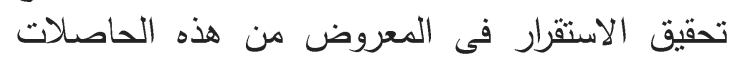

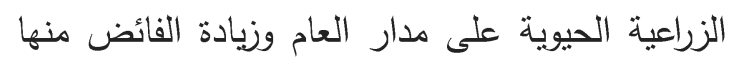

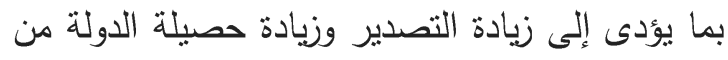
النقد الأجنبى ، ليس هذا زئس فقط بل إن إن معدلات نمو

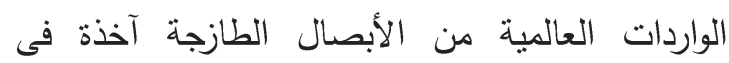

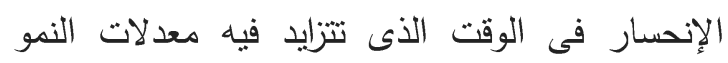

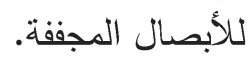

\section{هدف الدراسة}

يهدف البحث إلى دراسة الطرق التى يمكن بها الحد

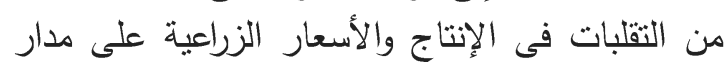

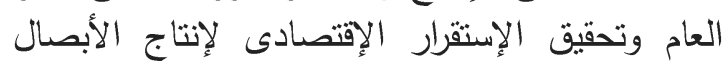

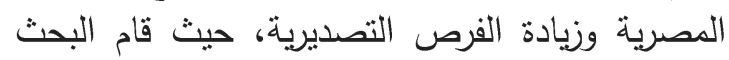

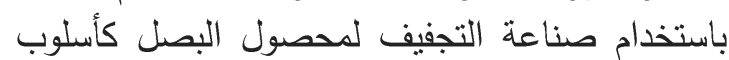

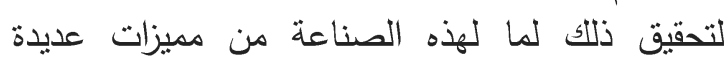


• زيادة إنتاجية البصل الثتوي المنفرد بمقدار

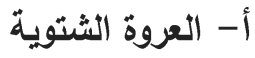

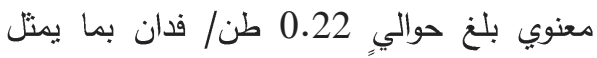

نحو 1.7 \% سنويا من متوسط الفترة البالغ حوالي اليا

أ - 1-1- البصل الثتوي المنفرد

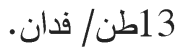

زيادة إنتاج البصل الثتوي المنفرد بمقدار معنوي

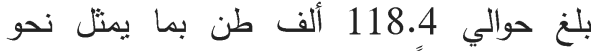

زيادة مساحة البصل الثتوي المنفرد بمقدار

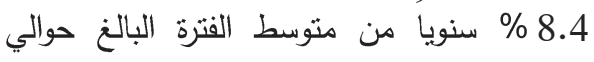

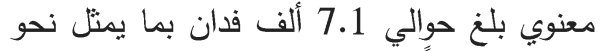

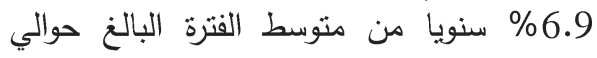

1418 ألف طن.

103 ألف فدان.

جدول 1. معادلات الاتجاه الزمني العام لمساحة وإنتاجية وإنتاج محصول البصل بجمهورية مصر العربية خلال بالإل

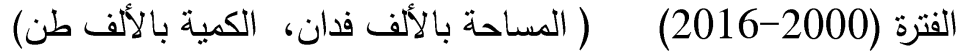

\begin{tabular}{|c|c|c|c|c|c|}
\hline ا ب التغنير & $\mathbf{F}$ & $\mathbf{R}^{2}$ & معادلة الاتجاه الزمني & \multicolumn{2}{|c|}{ البيان } \\
\hline 6.9 & 82.2 & 0.85 & $\begin{array}{l}\tilde{Y}_{\mathrm{i}}=39.1+7.1 \mathrm{X}_{\mathrm{i}} \\
(4.8)^{* *}(9.1)^{* * *}\end{array}$ & مساحة & \\
\hline 1.7 & 82.9 & 0.92 & $\hat{Y}_{i}=\frac{11.4+0.22 X_{i}}{(66.7)^{* * *}(11.5)^{* * *}}$ & إنتاجية & \\
\hline 8.4 & 117.98 & 0.89 & $\begin{aligned} \hat{Y}_{i}= & 352.1+118.4 X_{i} \\
& (10.9)^{* * *}(3.2) * * *\end{aligned}$ & إنتاج & \\
\hline-7.9 & 43.9 & 0.75 & $\begin{aligned} \hat{Y}_{i}= & 32.6-1.5 X_{i} \\
& (14.4)^{* * *}(-6.6)^{* * *}\end{aligned}$ & مساحة & \\
\hline 1.4 & 15.2 & 0.50 & $\begin{aligned} & \hat{Y}_{i}= 8.7+0.14 X_{i} \\
&(24.1)^{* * *}(3.9)^{* * *}\end{aligned}$ & إنتاجية & \\
\hline-6.1 & 22.1 & 0.60 & $\begin{aligned} \hat{Y}_{i}= & 293.2-11.5 X_{i} \\
& (11.7)^{* * *}(-4.7)^{* * *}\end{aligned}$ & إنتاج & \\
\hline-5 & 11.3 & 0.43 & $\begin{aligned} \hat{Y}_{i}= & 17.5-0.6 X_{i} \\
& (9.2)^{* *}(-3.4)^{* * *}\end{aligned}$ & مساحة & \\
\hline-- & 4.8 & 0.41 & $\begin{aligned} \hat{\mathrm{Y}}_{\mathrm{i}}= & 10.2+1.2 \mathrm{X}_{\mathrm{i}}-0.06 \mathrm{X}_{\mathrm{i}}^{2} \\
& (6.3)^{* *}(-2.6)(2.9)^{* *}\end{aligned}$ & إنتاجية & \\
\hline-- & 23.8 & 0.77 & $\begin{array}{r}\hat{Y}_{i}=102.9+34.7 X_{i}-2.3 X_{i}^{2} \\
(3.7)^{* * *}(-5.8)(4.8)^{* * *}\end{array}$ & إنتاج & \\
\hline-- & 14.9 & 0.68 & $\begin{aligned} & \tilde{Y}_{i}= 22.8-3.9 X_{i}+0.19 X_{i}^{2} \\
&(8.1)^{* *}(-5.4)^{* *}(4.95)^{* * *}\end{aligned}$ & مساحة & \\
\hline 4.1 & 38.6 & 0.72 & $\begin{aligned} & \hat{\mathbf{Y}}_{\mathrm{i}}= 4.6+0.33 \mathrm{X}_{\mathrm{i}} \\
&(8.4)^{* * *}(6.2)^{* * *}\end{aligned}$ & إنتاجية & \\
\hline-- & 4.5 & 0.39 & $\begin{aligned} \hat{Y}_{i}= & 58.2+19.1 X_{i}-0.97 X_{i}^{2} \\
& (2.3)^{* * *}(3.0)^{* *}(-2.8)^{* *}\end{aligned}$ & إنتاج & \\
\hline-- & 5.9 & 0.42 & $\begin{aligned} \hat{Y}_{i}= & 4.8+1.6 X_{i}-0.08 X_{i}^{2} \\
(2.5)^{* *}(-3.1) & (3.2)^{* * *}\end{aligned}$ & مساحة & \\
\hline 0.6 & 6.3 & 0.29 & $\begin{aligned} & \hat{Y}_{i}= 11.7+0.07 X_{i} \\
&(42)^{* * *}(2.5)^{* * *}\end{aligned}$ & إنتاجية & \\
\hline-- & 4.5 & 0.39 & $\begin{aligned} \bar{Y}_{i}= & 58.02+19.1 X_{i}-0.97 X_{i}^{2} \\
& (2.3)^{* *}(-2.8)(2.97)^{* * *}\end{aligned}$ & إنتاج & \\
\hline
\end{tabular}

حيث :

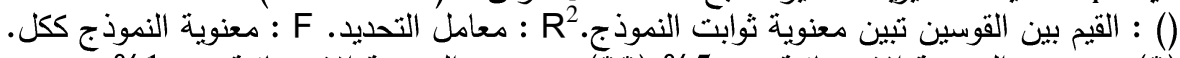

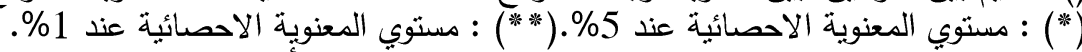

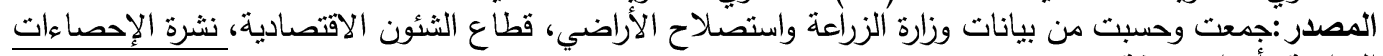

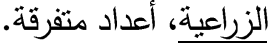


اقتصادي مجزي وزيادة حصيلة الصادرات المصرية من الإني النقد الأجنبي، الامر الذي يمكننا من تقليل نسبة الفاقد

$$
\text { ب- بالاستفادة منه. }
$$

- انخفاض مساحة البصل الصيفي المنفرد بمقدار

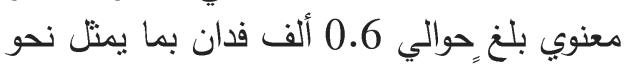
5 \% سنويا من منوسط الفترة البالغ حوالي 12 ألف فدان. - إنتاجيةٍ البصل الصيفي المنفرد أخذت اتجاهاً

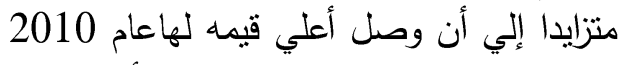

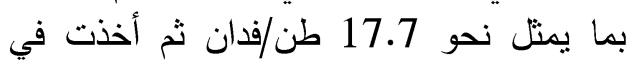

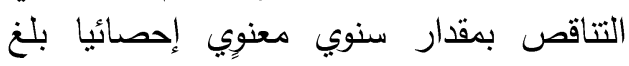

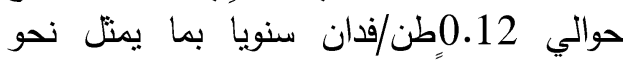
\% 0.8 سنوياً من متوسط الفنترة البالغ حوالي 15 طن/ فدان. - إنتاج البصل الصيفي المنفرد أخذ اتجاها متزايدا

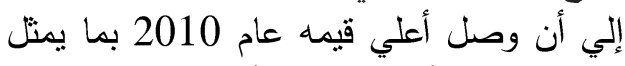
نحو 290.4 ألف طن ثم أخذا فيمه في التناقص بمقدار سنوي معنوي إحصائيا بلغ حوالي

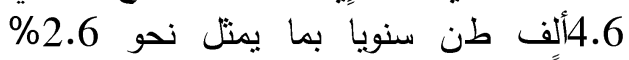
سنوياً من متوسط الفترة البالغ حوالي 177 ألف بن طن.

\section{إمكانية تجفيف البصل الصيفي المنفرد في مصر}

أوضحت نتائج الدراسة أن نحو 86.75\% من من النقا

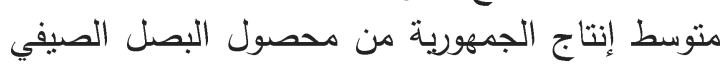
المنفرد تتركز في محافظات (الجيزة- منطقة النوبارية-

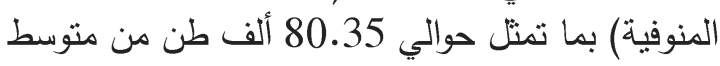
إنتاج الجمهورية خلال فترة الدراسة، وهي تمنتل كمية

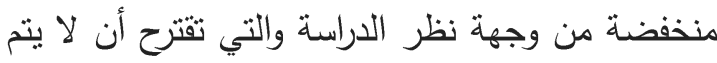

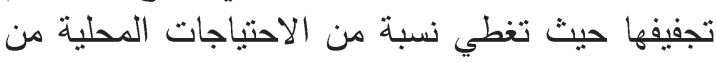

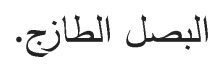

إمكانية تجفيف البصل الشتوي المنفرد في مصر

أوضحت نتائج الدراسة أن نحو 74.91\% من النتاج

متوسط إنتاج الجمهورية من محصول البصل الثنتوي الترائ

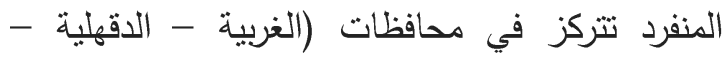

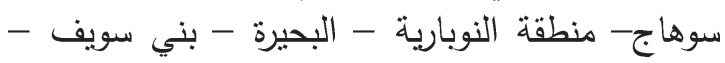
الفيوم) خلال فترة الدراسة، الأمر الذي يحتاج إلي القامة الذية

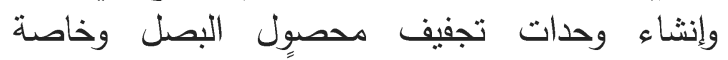
بمحافظتي الغربية والدقهلية نظرا لتركز إنتاج البصل

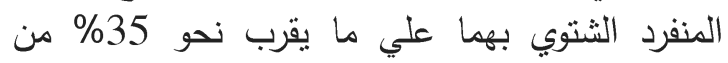

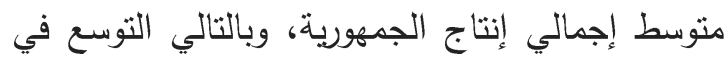

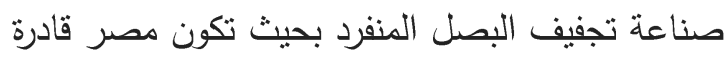
علي التصدير والمنافسة للاسواق العالمية حيث أنيف أنها

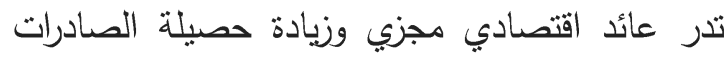

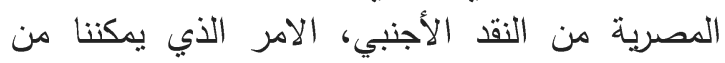
تعظيم الاستفادة مع تدنية الفاقد منه فى آن واحد.

$$
\text { أ-2- أبصل الثتوي المحمل }
$$

انخفاض مساحة البصل الثنتوي الدحمل بمقدار معنويٍ

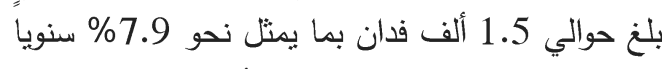
من منوسط الفترة البالغ حوالي 19 ألف فدان. زيادة إنتاجية البصل الثنوي المحمل بمقدار معنوي بلغِ

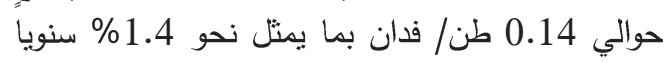
من منوسط الفترة البالغ حوالي 10 طن/ فل فدان.

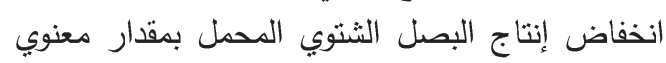

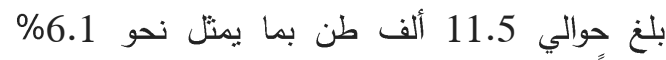
سنويا من متوسط الفترة البالغ حوالي 189 ألف طن.

$$
\text { إمكانية تجفيف البصل الشتوي المحمل في مصر }
$$

تنين من نتائج الدراسة أن نحو

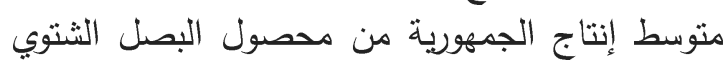

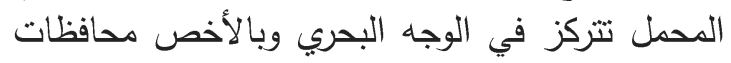

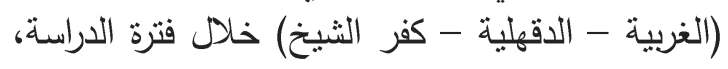

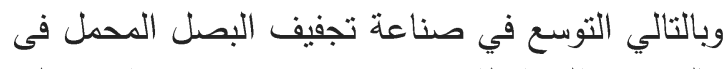

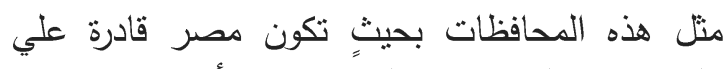

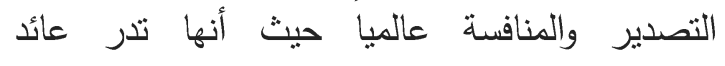


1.6 سنوياً من منوسط الفترة البالغ حوالي 10 ألف فدان. - إنتاجيةٍ البصل النيلي المنفرد أخذت اتِاهاً

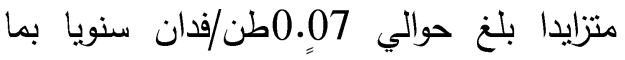
يمثل نحو 0.6\% سنويا من متوسط الفترة البالغ حوالي 12 طن/ فدان. - إنتاج البصل النيلي المنفرد أخذ اتجالهاً متزايداً

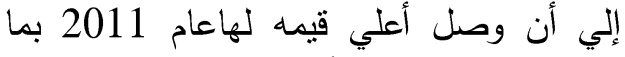

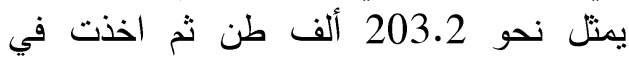

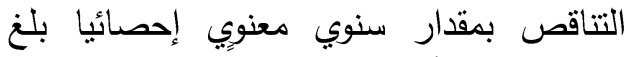

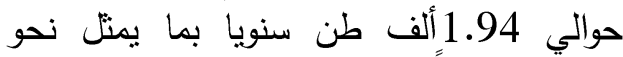

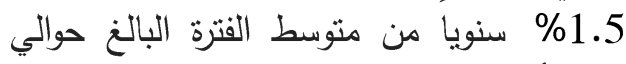
128 ألف طن.

التوزيع الجغرافى للصادرات المصرية من البصل المجفق

تعد ألمانيا أهم مستورد للبصل المصري المجفف منف المباد بنسبة 28.8\% من متوسط إجمالى صادرات البصل المصري بمتوسط كمية قدرها 3448 طن كمتوسط النمالية

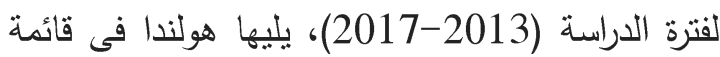
اهم الدول المستوردة للبصل المجف المصنري بمنتوسط

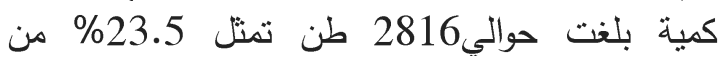
متوسط صادرات مصر من البصل المجفف، وجاءت

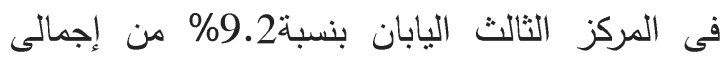

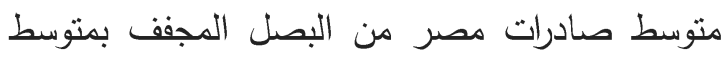
كمية قدرها 1102 طن، ثم فى المراكز الأخرى اليونان ثم بلجيكا ثم بريطانيا ثم البرازيل على التوالي.
ب-2- البصل الصبفي المحمل - أخذت مِساحة البصل الصيفي المحمل اتجاها

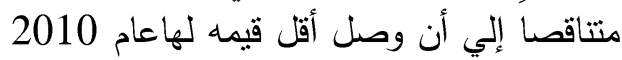

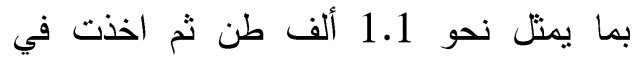
التزايد بمقدار سنوي معنوي إحصائيا بلغ حوالي

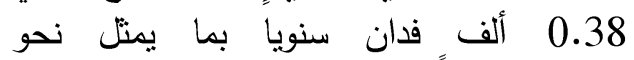
4.75\% سنويا من متوسط الفترة البالغ حوالي 8 اليا 8 ألف فدان. - زيادة إنتاجية البصل الصيفي المحمل بمقدار

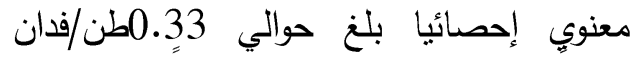

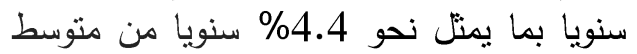
الفترة البالغ حوالي 8 طن/ فدان.

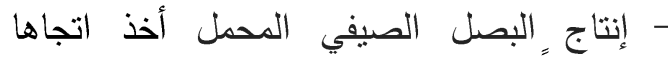
متزايدا إلي أن وصل أعلي قيمه لهاعام 2003

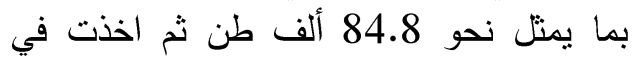
التتاقص بمقدار سنوي معنوي إحصائيا بلغ

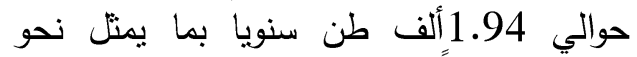

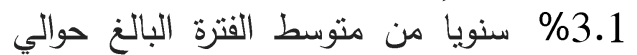
64 ألف طن.

\section{ج-العروة النيلية (البصل النيلي المنفرد)}

- مساحةٍ البصل النيلي المنفرد أخذت اتجاهاً متزايداً إلي أن وصل أُعلي قيمه لهاعام 2010 بما يمثل نحو 16.5 ألف فدان ثم أخذت في لئ التناقص بمقدار سنوي معنوي إحصائيا بلغ فئ فئ

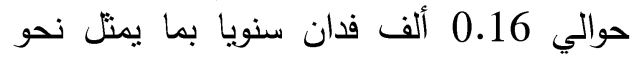
جدول 2. الأهمية النسبية للتوزيع الجغرافى لصادرات مصر من البصل المجف (بالطن) لدول العالم خلال الفترة

\begin{tabular}{|c|c|c|c|c|c|c|c|}
\hline الأهمية النسبية & المتوبط & 2017 & 2016 & 2015 & 2014 & 2013 & الدولة / السنوات \\
\hline 28.8 & 3448 & 1876 & 3159 & 4441 & 4415 & 3348 & ألمانيا \\
\hline 23.5 & 2816 & 5577 & 3884.5 & 2192 & 1606 & 819 & هولتدا \\
\hline 9.2 & 1102 & 1729 & 1308 & 887 & 914 & 672 & اليابان \\
\hline 6.2 & 742 & 371 & 753 & 1135 & 875 & 578 & اليونان \\
\hline 5.0 & 594 & 379 & 364 & 349 & 964 & 915 & بلجيكا \\
\hline 4.7 & 566 & 167 & 501 & 835 & 910 & 417 & المملكة المتحدة \\
\hline 3.1 & 376 & 424 & 348 & 272 & 598 & 237 & البرازيل \\
\hline 19.4 & 2319 & 2409 & 2707 & 3005 & 1870 & 1605 & أخري \\
\hline 100.0 & 11963 & 12932 & 13024 & 13116 & 12152 & 8591 & العالم \\
\hline
\end{tabular}

المصدر : جمعت وحسبت من بيانات موقع Trade map شبكة الإنترنت. 
على البصل المصرى المجفف وإن كانت سالبة الميل

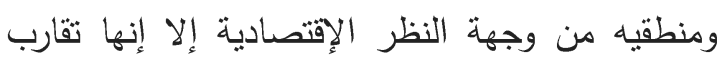

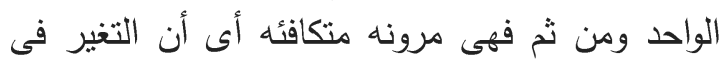

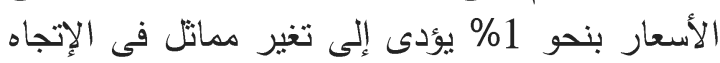

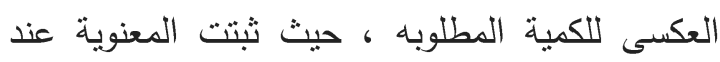

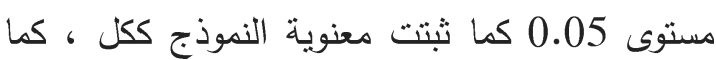

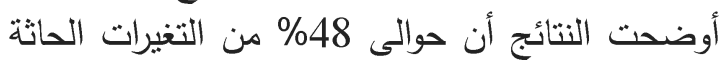

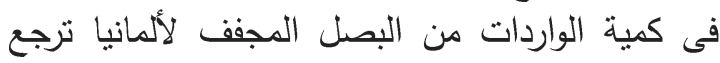
للمتغيرات المستقلة محل الدراسة.

2ـ دالة طلب هولندا على وارداتها من البصل المصرى المجفف

$$
\begin{array}{cccc}
\text { Ln } Q_{\text {neth }}= & 10.7 & -0.9 \operatorname{Ln} P_{\text {eg }} & +0.4 \operatorname{Ln} P_{\text {france }} \\
& (4.7)^{\star \star} \quad(-2.5)^{\star \star} & (1.14)^{\star \star} \\
R^{2}=0.33 \quad \text { Adj. } R^{2}=0.24 & F=3.5^{\star \star}
\end{array}
$$

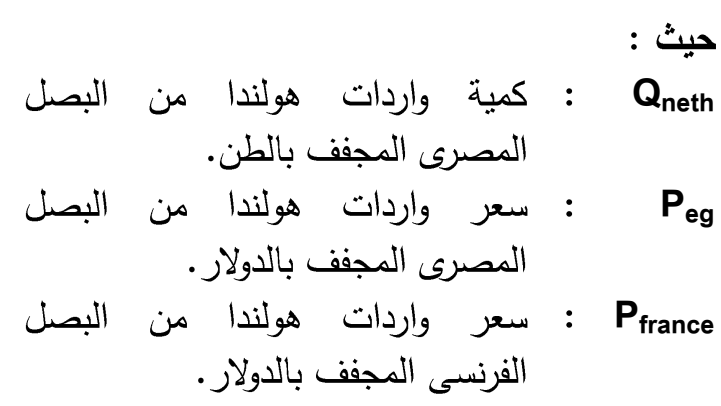

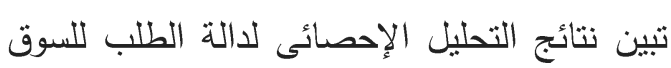

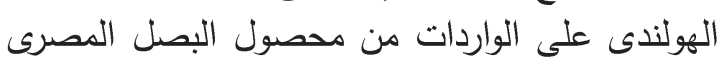
المجفف خلال فترة الدراسة (2001-2017) أن زيادة النقاد سعر واردات هولندا من البصل المجفف الفرنسى بنسبة البنة

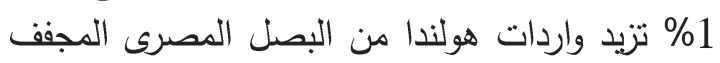

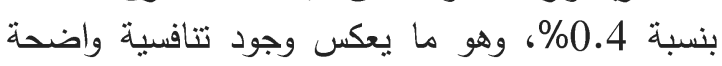

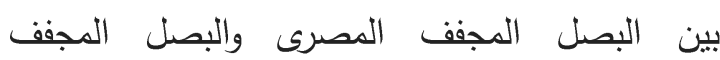
الفرنسى. وهو ما يعنى أن المرونه المشنقة أقل من البهل الواحد ومن ثم فهى طلب غير فير مرن أى لا يتأثر كثيراً بالأسعار المنافسة. فى حين أنه بزيادة سعر واردات هولندا من البصل

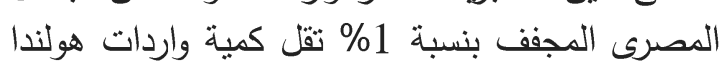

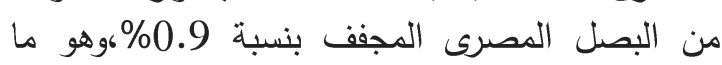

ثانيا: نتائج التحليل الإحصائى لاوال الطلب لأهم

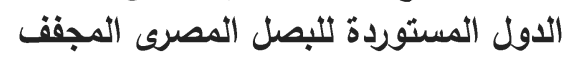

أعتمدت الدراسة على الواردات للاول المختلفةٍ

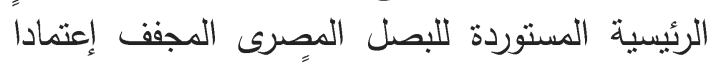

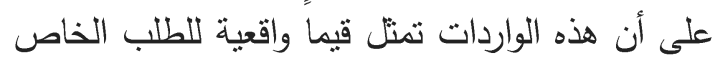
بكل دولة على المحاصبل المختلفة.

1ـ دالة طلب ألمانياعلى وارداتها من البصل المصرى المجفف $\begin{array}{llll}\operatorname{Ln} Q_{\text {ger }}=-10.8 & -0.9 \operatorname{Ln} & +1.64 \operatorname{Ln} & +1.65 \mathrm{Ln} \\ & P_{\text {eg }} & P_{\text {india }} & P_{\text {usa }}\end{array}$

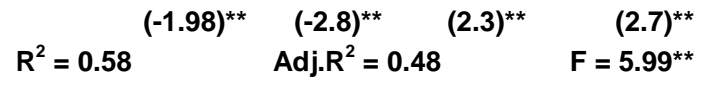

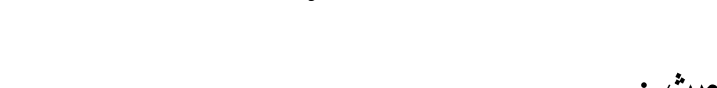
Qger المجفف بالطن.

: : Peg المجفف بالدولار .

: : $\mathbf{P}_{\text {indi }}$

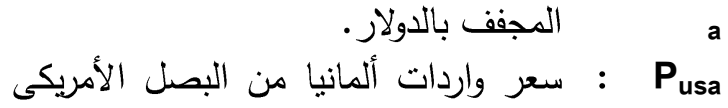
المجف بالدولار . توضح نتائج التحليل الإحصائى لدالة الطالب الطانب

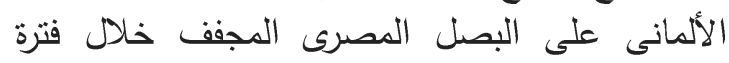
الدراسة (2001-2017) أن زيادة سعر واردات ألمانيا من البصل المجفف الهندى وكذلك الأمريكى بنسبة

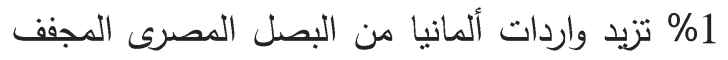

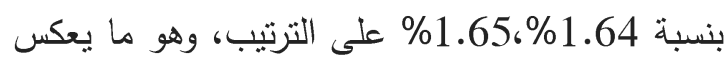

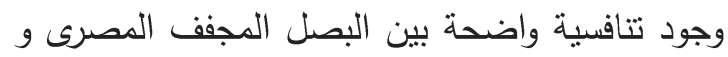
كل من البصل المجفف الهندى والأمريكى.

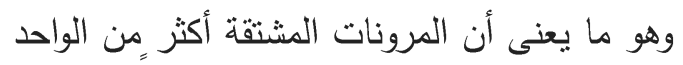
ومن ثم فهى طلب أكثر مرونة ويتأثر كثيراً بالأسعار العنار المنافسة.

فى حين أنه بزيادة سعر واردات ألمانيا من البصل

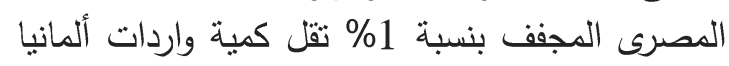
بنسبة 0.9\% ، وهو ما يعنى أن مرونة الطلب السعرية 
من البصل المصرى المجفف بنسبة 0.55\% ، وهو ما

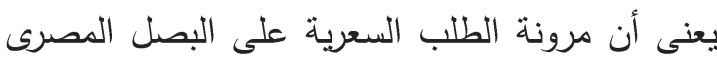

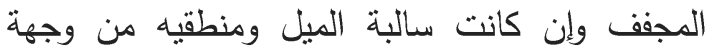

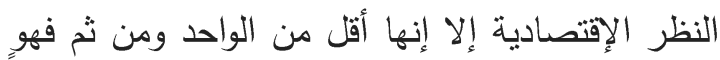
طلب غير مرن أى أن كمية الواردات لا تثأنز كثيرا

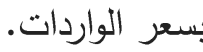
حيث ثبتت المعنوية عند مستوى 0.05 كما ثبتت

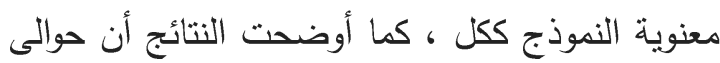

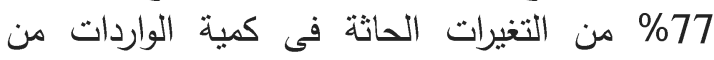
البصل المجف لليابان ترجع للمتغيرات المستقلة محل

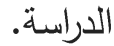
4ــ دالة الطلب البلجيكى على وارداتها من البصل المصرى المجفف

$\begin{array}{lll}\operatorname{Ln} Q_{\mathrm{Bel}}=3.04-2.5 \mathrm{Ln} P_{\mathrm{eg}} & +1.1 \mathrm{Ln}+1.65 \mathrm{Ln} \\ & P_{\text {spain }} P_{\text {india }}\end{array}$ $\begin{array}{llll}(0.68) & (-3.6)^{\star *} \quad(2.4)^{\star} \quad(2.03)^{*}\end{array}$ $R^{2}=0.54 \quad$ Adj. $R^{2}=0.44 \quad F=5.1^{* *}$

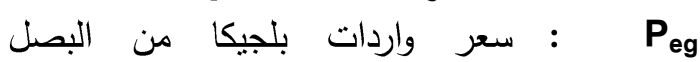

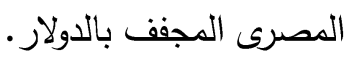

Pindia

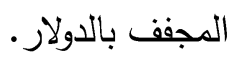

Pspain الأسبانى المجفف بالدولار .

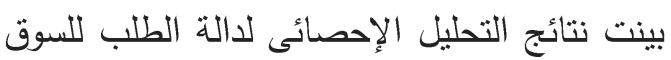

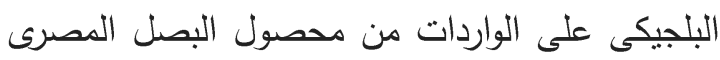

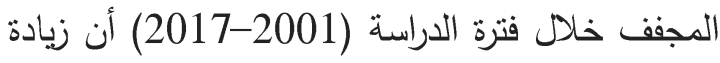
سعر واردات بلجيكا من البصل المجفف الهندى وكذللك

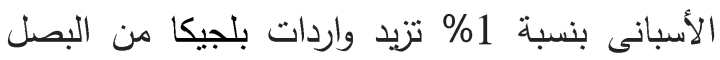

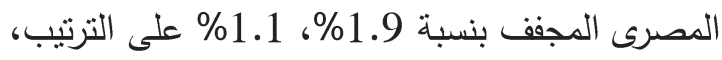
وهو ما يعكس وجود تتافسية واضحة بين البصل

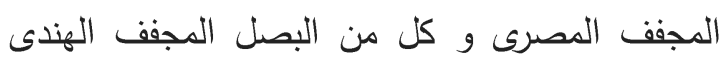

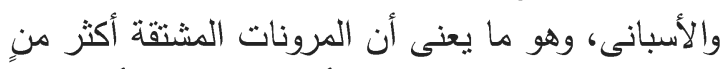

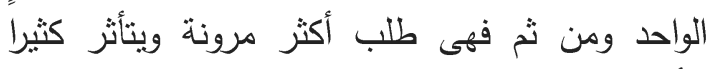

يعنى أن مرونة الطلب السعرية على البصل المصرى

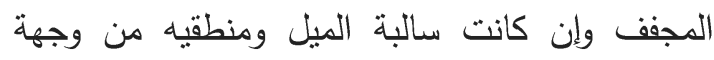

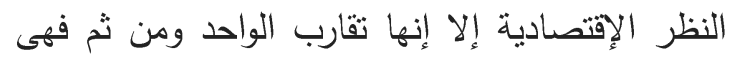

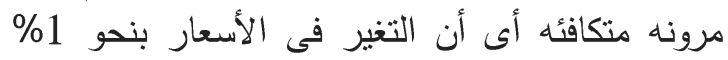

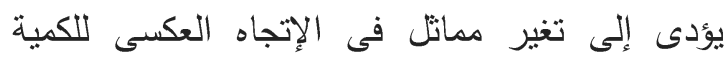

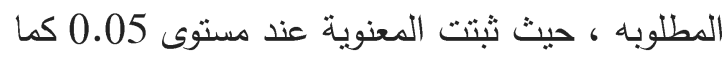

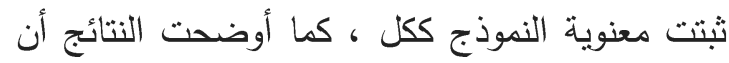

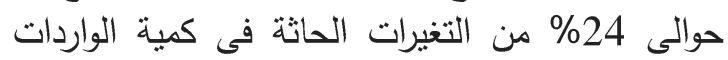
من البصل المجف لهول لهولندا ترجع للمتغيرات المستقلة فئة الوردات

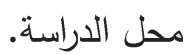

3ـ دالة طلب اليابان على وارداتها من البصل المصرى المجفف

\begin{tabular}{|c|c|c|c|c|}
\hline$n$ & -346.2 & -0.55 & $+4.3 \mathrm{Ln}$ & +6 \\
\hline $\mathbf{Q}_{\text {Japa }}$ & & $\begin{array}{c}\operatorname{Ln} P_{e g} \\
(-0.81)\end{array}$ & $\begin{array}{l}\mathrm{I}_{\mathrm{Japan}} \\
(5.9)^{\star \star}\end{array}$ & $\begin{array}{l}\text { Pop Japan } \\
(2.8)^{\star \star}\end{array}$ \\
\hline & $\mathrm{Ad}$ & 0.7 & & $F_{-}$ \\
\hline
\end{tabular}

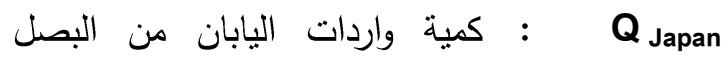
المصرى المجفف بالطن.

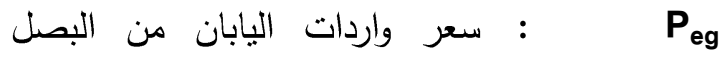
المصرى المجفف بالدولار .

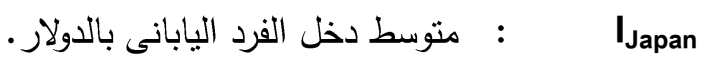
PopJapan

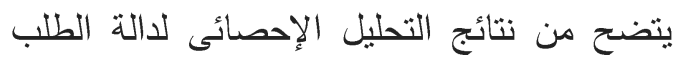
للسوق اليابانى على الواردات من محصول الإحلى البصل البهل

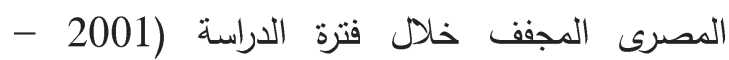
2017) أن زيادة منوسط دخل الفرد اليابانى،وكذلك التك

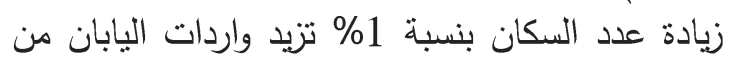

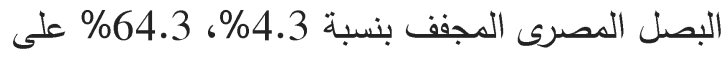

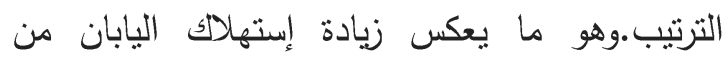
البصل المجفف المصرى بزيادة الاخل وتوافق المنتج

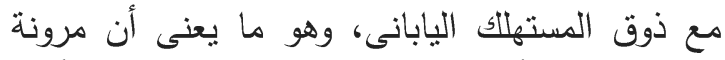

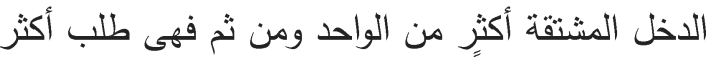
مرونة ويتأثر كثيرا بالاخل. فى حين أنه بزيادة سعر واردات الئن اليابان من البصل المصرى المجف بنسبة 1\% تقل كية واردات اليابان 
بنسبة 1.2\% ،وهو ما يعنى أن مرونة الطلب السعرية

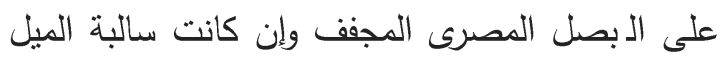
ومنطقيه من وجهة النظر الإقتصادية إلا إنها أكبر من النه الكيل

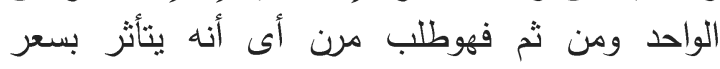

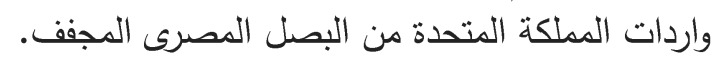

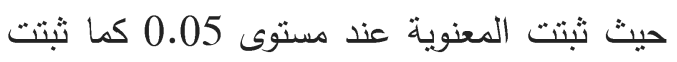

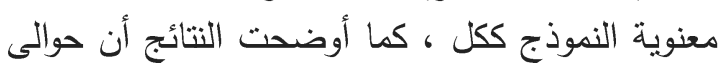

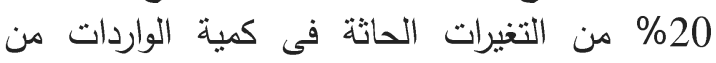

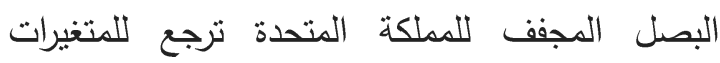
المستقلة محل الدراسة.

6ـ دالة الطلب لواردات سوق البرازيل من محصول

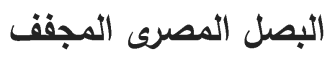
Ln $Q_{\text {Brazil }}=-67.5$
$-0.13 \operatorname{Ln} P_{\text {eg }}+14.1 \operatorname{Ln}$
$(-2.6)^{\star \star}$
$(-0.2)$
Pop Brazil
$(2.5)^{\star}$
$R^{2}=0.61$
$\operatorname{Adj} . R^{2}=0.54 \quad F=7.9^{\star \star}$

: حيث

Q Q $\quad$ Brazil المصرى المجفف بالطن.

: سعر واردات البرازيل من البطن البصل

المصرى المجفف بالدولار .

Pop Brazil

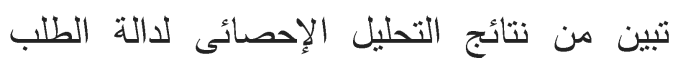

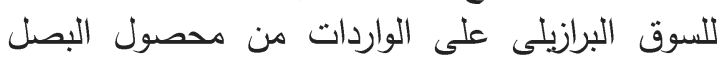

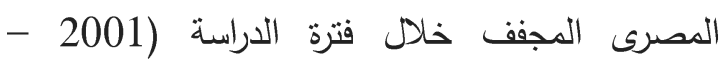

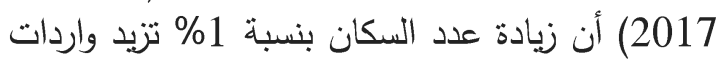

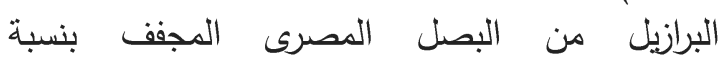
14.1\%.وهو ما يعكس زيادة إستهلالك البرازيل من البهن

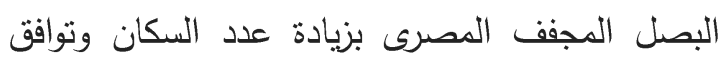
المنتج مع ذوق المستهلك البرازيلى. فى حين أنه بزيادة سعر واردات البرازيل من البصل البصل

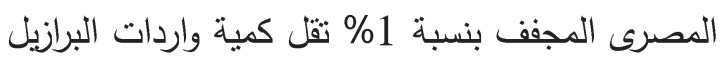

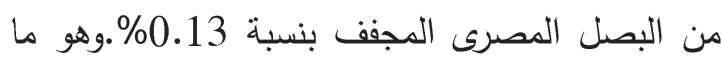

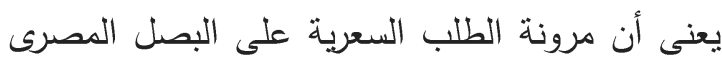

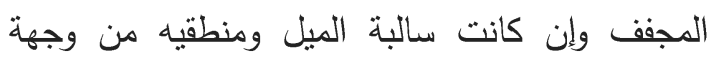

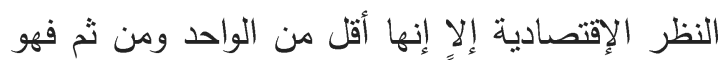

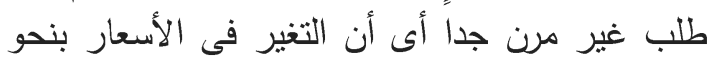
1\% يؤدى إلى إنخفاض كمية واردات البرازيل بنسبة النية
فى حين أن زيادة سعر واردات بلجيكا من البصل المصرى المجفف بنسبة 1\% زيادة تقل كمية واردات بلجيكا

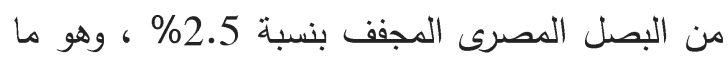
يعنى أن مرونة الطلب السعرية على البصل البفل المصن

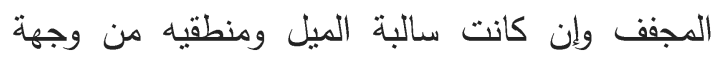
النظر الإقتصادية إلا إنها أكبر من الواحد ومن ثم فئ فهو

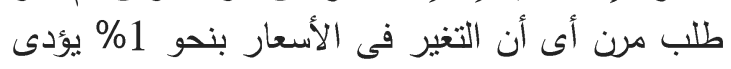
إلى تغير أكبر فى الإتجاه العكسى لكمية الواردات.

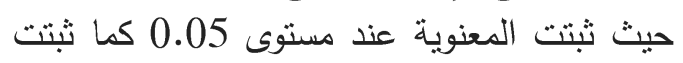

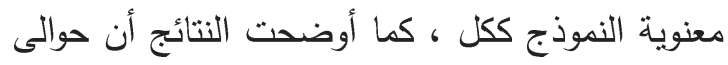

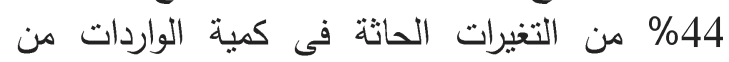

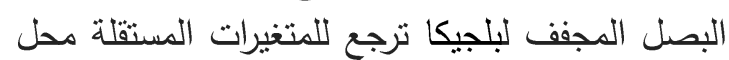
الدراسة.

5ـ دالة طلب المملكة المتحدة على وارداتها من البه البصل المصرى المجفف

$\operatorname{Ln} Q_{\mathrm{uk}}=\quad 9.4 \quad-1.2 \operatorname{Ln} P_{\mathrm{eg}}+0.8 \mathrm{Ln} P_{\text {france }}$

$$
(2.4)^{*} \quad(-2.4)^{*} \quad(1.6)
$$

$R^{2}=0.29 \quad$ Adj. $R^{2}=0.20 \quad F=2.97^{*}$

حيث : البصل المصرى المجفف بالطن.

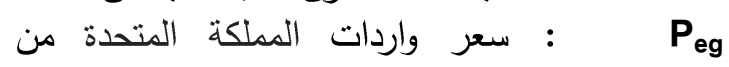
البصل المصرى المجفف بالدولار .

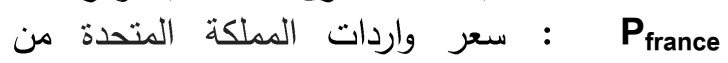

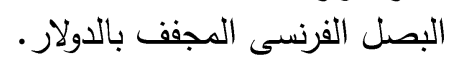

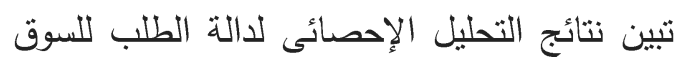

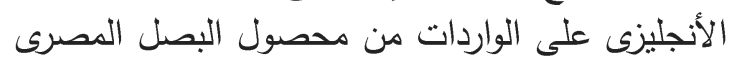

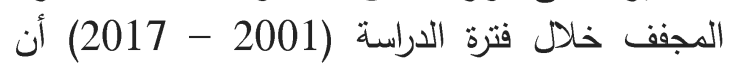

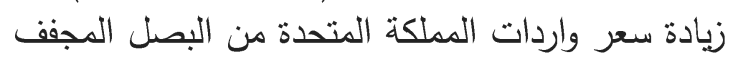

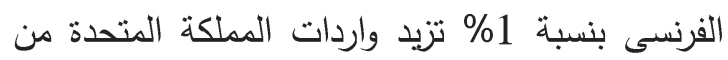

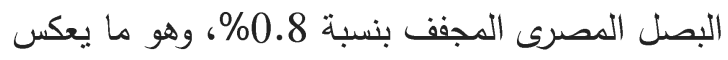

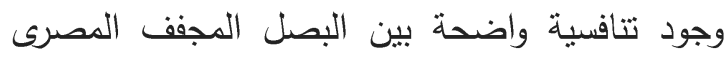

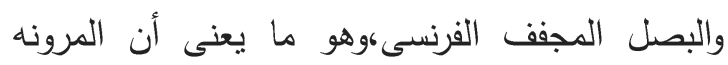

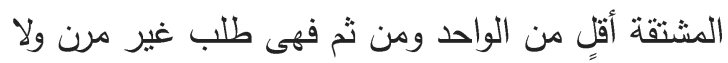
يتأثر كثيراً بالأسعار المنافسة. فى حين أنه بزيادة سعر واردات المملكة المتحدة المئة

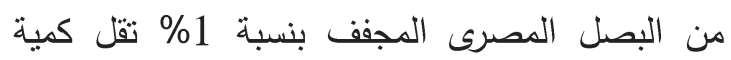
واردات المملكة المتحدة من البصل المصرى المجفف لمبف 
2- أوضحت نتائج تحليل دالة الطلب اليابانى على مالى الئى

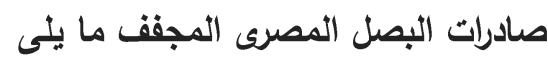

توضح نتائج التحليل الإحصائى لدالة الطلب

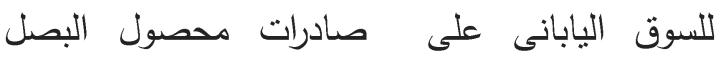
المصرى المجفف خلال فترة الدراسة (2001- 2017)

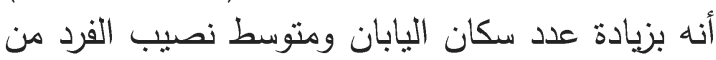
الدخل اليابانى بنسبة1\% لكل منهما يؤدى ذللك إلى إنى

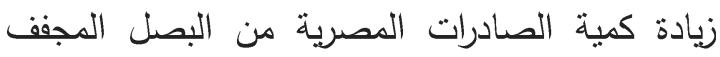

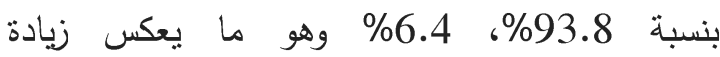
الاستهلاك من البصل المجفف المصرى بزيادة عدد

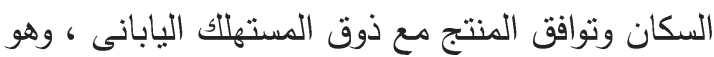
ما يعنى أن مرونة الدخل المشتقة أكثِرِ من الواحد ومن المن ثم فهى طلب أكثر مرونة ويتأثز كثيرا بالدخل.

$\operatorname{LnQ}_{\text {Japan }}=\begin{array}{llll}-511.3 & -0.51 & +93.8 & +6.4\end{array}$ Ln $P_{\text {eg }} \quad$ Ln Pop Japan $\quad$ Ln I Japan $(-1.8)^{\star} \quad(-1.1) \quad(1.9)^{\star} \quad(3.4)^{\star *}$ $R^{2}=0.67 \quad$ Adj. $R^{2}=0.60 \quad F=8.84^{\star *}$

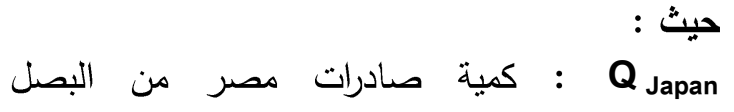
المجفف للسوق اليابانى بالطن.

: $\quad$ Peg $_{\text {er }}$ المجفف للسوق اليابانى بالدولار .

I Japan Pop

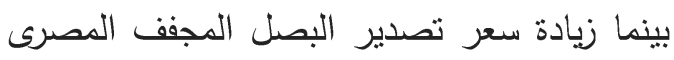
يترتب عليه تتاقص كمية صادرات مصر من البصل

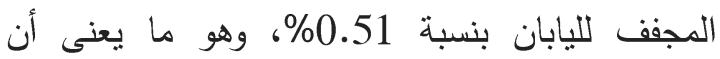
مرونة الطلب السعرية على البصل المصرى المجفية لإنى

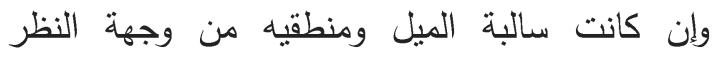

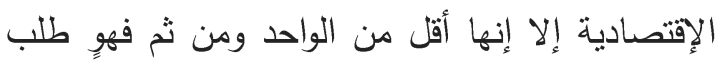

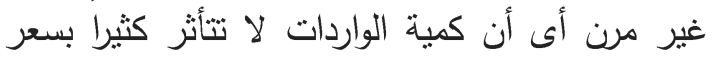

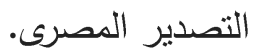

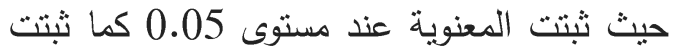

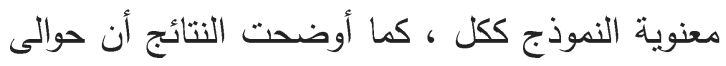

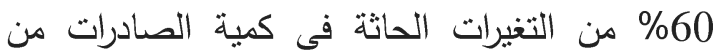

0.130

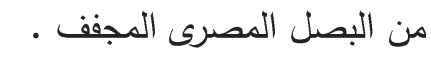
حيث ثبتت المعنوية عند مستوى 0.05 كما ثنتت التها معنوية النموذج ككل ، كما أوضحت النتائج أن حوالى كنى

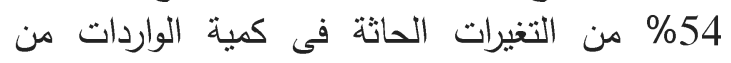

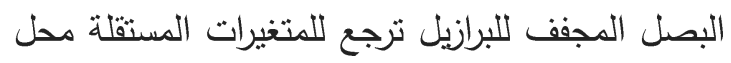

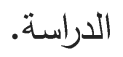

ثانياً: نتائج التحليل الإحصائى لدوال الطلب لأهم

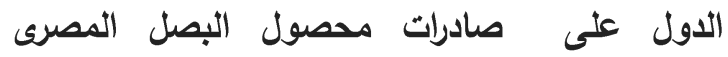
المجفف

1-دالة الطلب الهولندى على صادرات البصل المصرى المجفف بدون متغير الاخل

$$
\begin{array}{lrl}
\operatorname{Ln} Q_{\text {neth }} & -389.3-1.36 \operatorname{Ln} P_{\text {eg }}+24.5 \operatorname{Ln} \\
= & P_{\text {opeth }}
\end{array}
$$

$R^{2}=0.39 \begin{array}{rrr}(-2.9)^{\star *} & (-2.8)^{\star *} & (2.97)^{\star *} \\ \text { Adj. } R^{2}=0.30 & F=4.44^{\star *}\end{array}$

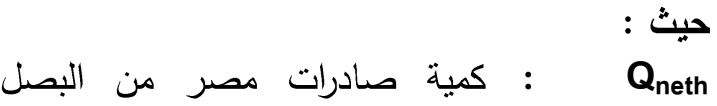
المجفف للسوق الهولندى بالطن. Peg المجفف للسوق الهولندى بالدولار .

Pop neth

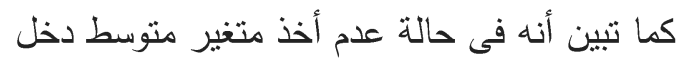
الفرد فى الاعتبار فيتضح أنه بزيادة عدد السكان بدولة ألة فئلة

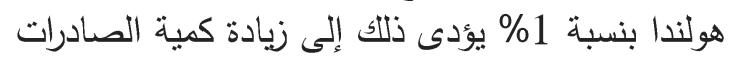

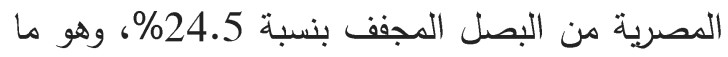

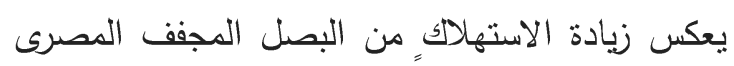
بزيادة عدد السكان أيضاً.

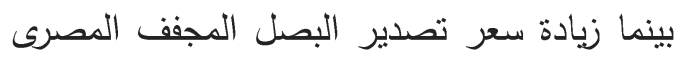
يترتب عليه تتاقص كمية صادرات مصر من البصل المجفف لهولندا بنسبة 1.36\%،وهو كأبن ما يعنى أن مرونة

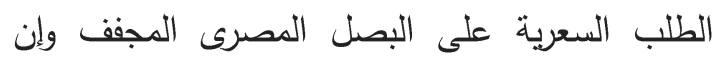

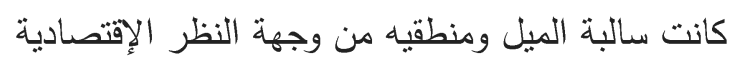

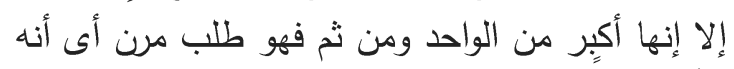
يتأثز كثيرا بسعر تصدير مصر الأنر 
المجف للسوق البلجيكى بالطن.

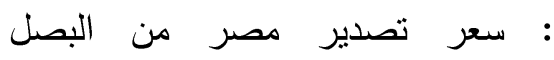

المجف للسوق البلجيكى بالدولار .

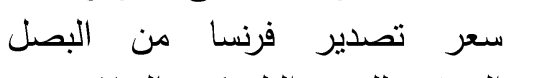

المجف للسوق البلجيكى بالدولار . Pspain المجفف للسوق البلجيكى بالدولار.

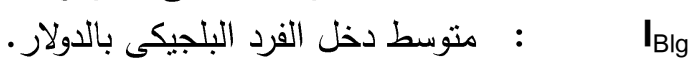

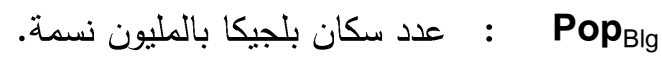
: : Peg fresh

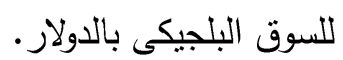

فى حين زيادة كل من سعر تصدير لالإلار. البصل المجف المصرى بنسبة 1\% من نتاقص كمية صادرات مصر من البصل المجفف للسوق البلجيكى بنسبة

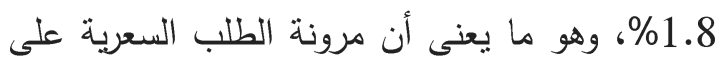

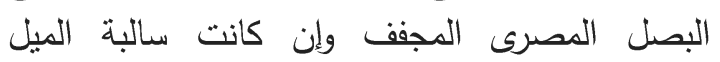

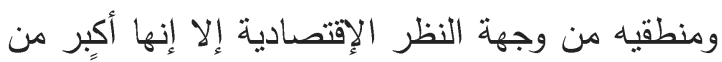

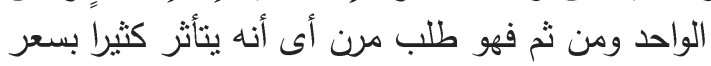

\section{حيث ثثتت المعنوية الإحصائية عند مستوى 0.05}

$$
\text { تصدير مصر • }
$$

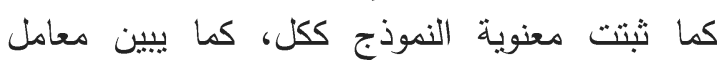

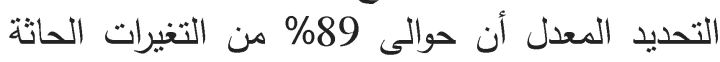

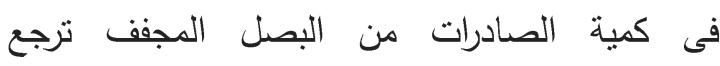
للمتغيرات المستقلة محل الدراسة.

4-دالة طلب المملكة المتحدة على صادرات البصل المصرى المجفف طالب المع

أظهرت نتائج التحليل الإحصائى لدالة الطلب

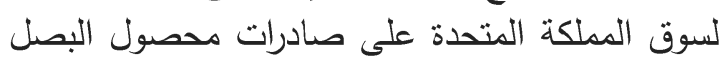
المصرى المجفف خلال فترة الدراسة (2001- 2017)

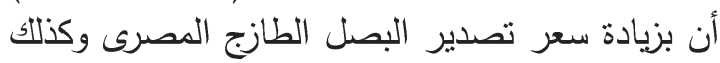

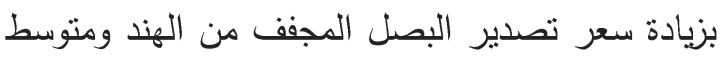
نصيب الفرد من الدخل الإنجليزى وعدد سكان المكلة الهنة

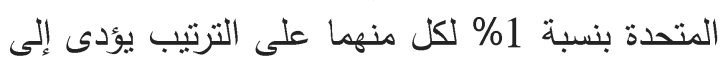

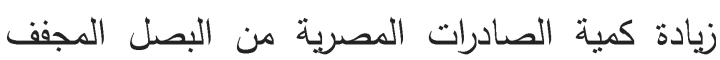

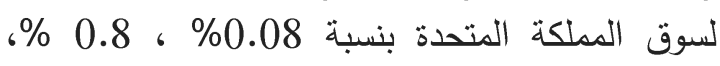
11.2 على الترتيب ، وهو ما يعكس وجود تنتافسية

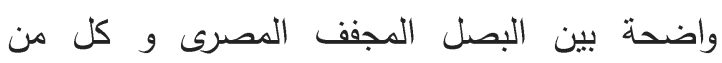

البصل المجفف لليابان ترجع للمتغيرات المستقلة محل

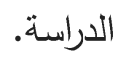

3- دالة الطب البلجيكى على صادرات البصل المصرى المجفف

توضح نتائج التحليل الإحصائى لدالة الطلب

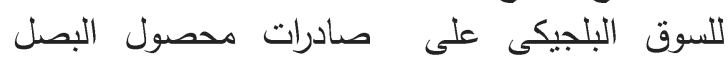

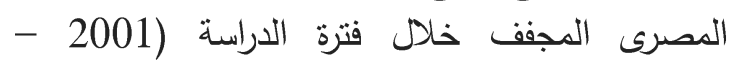
2017) أن زيادة سعر تصدير البصل الطازج المصربوكذلك بزيادة سعر تصدير البصل المجفف لكل

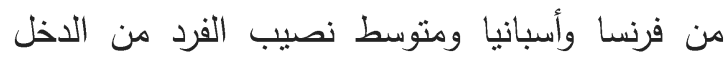

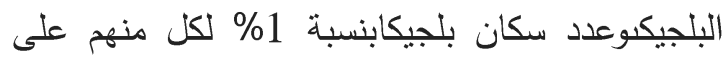

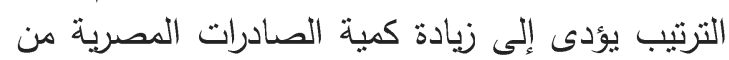

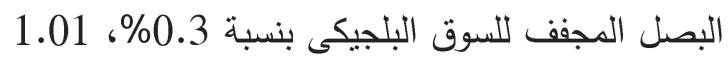

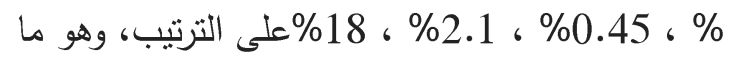

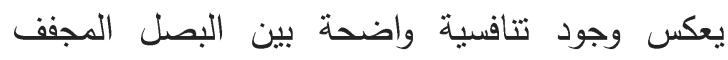
المصرى و كل من البصل الطازج المصرى والبـ والبصل

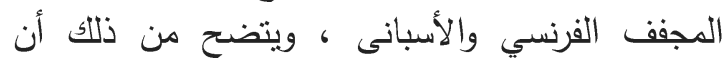

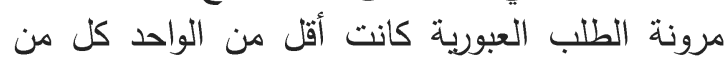
سعر البصل الطازج وسعر تصدير أسبانيا وهو ما لإِ يعنى أن الطلب لهما غير مرن وهو لايتأثر كثيراً

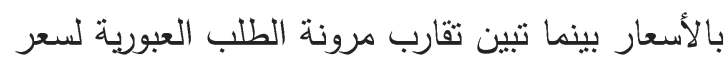

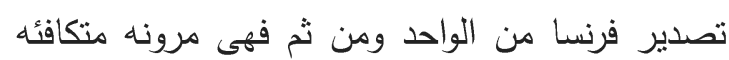

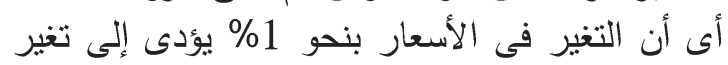
مماتل فى الإتجاه العكسى للكمية المطلوبه.

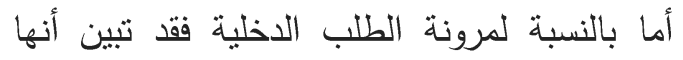

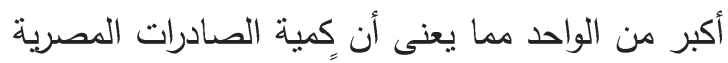

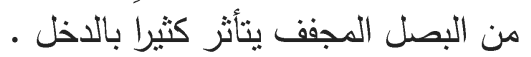

$$
\begin{array}{llll}
\operatorname{Ln} Q_{B \mid g}=28.1 & -1.8 & +0.3 & +1.01 \\
& \operatorname{Ln} P_{\text {eg }} & \operatorname{Ln} P_{\text {eg fresh }} & \operatorname{Ln} P_{\text {france }}
\end{array}
$$$$
(6.3)^{\star \star}(-4.6)^{\star \star} \quad(2.7)^{\star \star} \quad(3.5)^{\star \star}
$$

+0.45 Ln $\mathrm{P}_{\text {spain }}+18 \mathrm{Ln} \mathrm{Pop}_{\mathrm{Blg}}+2.1 \mathrm{Ln} \mathrm{I}_{\mathrm{Blg}}$

$$
(2.1)^{\star}
$$

$(2.2)^{*}$

$R^{2}=0.93$

Adj. $R^{2}=0.89$

$\mathrm{F}=22.5^{\star *}$

حيث : $\begin{aligned} & \text { Q } \\ & \mathbf{Q}_{\mathrm{Blg}}\end{aligned}$ 
5- دالة طلب البرازيل على صادرات البصل المصرى

المجفت

توضح نتائج التحليل الإحصائى لدالة الطلب

للسوق الهولندى على صلى صادرات محصول الإحلى البصل المصرى المجفف خلال فترة الدراسة (2001- 2017) أنه بزيادة متوسط نصيب الفرد من الاخل البرازيلى بنسبة 1\% يؤدى ذلك إلى زيادة كمية الصادرات

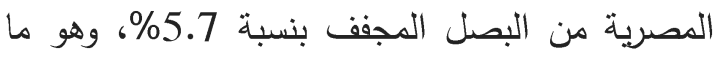
يعكس زيادة إستهلالك البرازيل من البصل الئل المفف

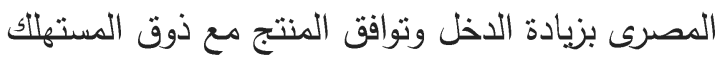

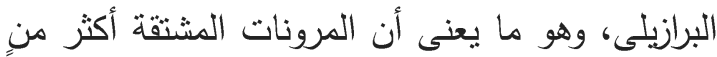
الواحد ومن ثم فهى طلب أكثر مرونة وينأثز كثيرا بالأسعار المنافسة.

Ln Q $Q_{\text {Brazil }}=\quad$-35.5 $\quad-1.7$ Ln $P_{\text {eg }}+5.7$ Ln I $(-2.6)^{\star \star} \quad(-1.9)^{\star \star} \quad(3.0)^{\star \star}$

$\mathrm{R}^{2}=\mathbf{0 . 4 8} \quad$ Adj. $\mathrm{R}^{2}=0.38 \quad \mathrm{~F}=4.6^{\star \star}$

: حيث

Q Q Q لسوق البرازيل بالطن.

Peg

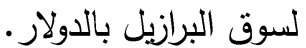

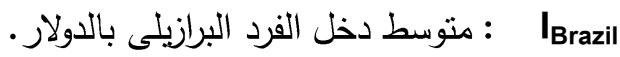

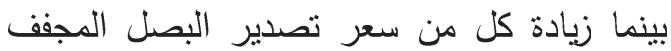

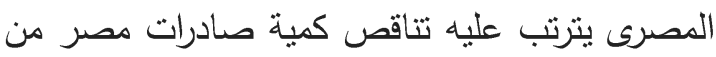

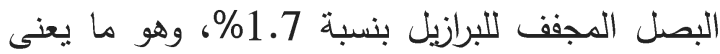

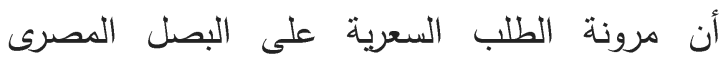
المجفف وإن كانت سالبة الميل ومنطقيه من وجهة النهاية

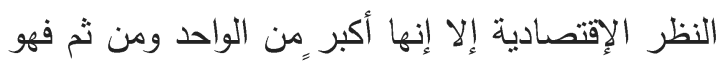

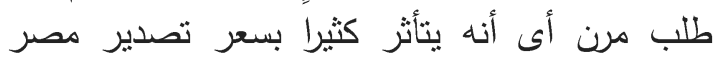
للبصل المجفف.

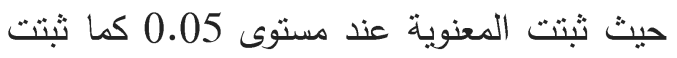

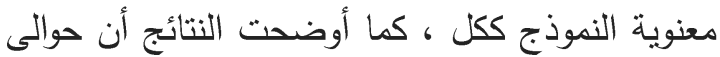

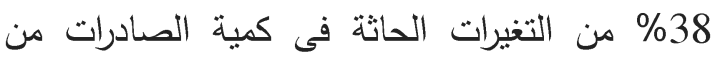
البصل المجف للبرازيل ترجع للمتغيرات المستقلة محل

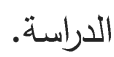

البصل الطازج المصرى والبصل المجف الهندى ، وهو

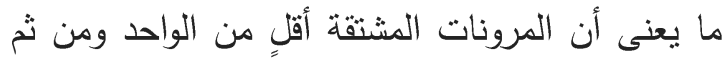
فهى طلب غير مرن ولا يتأثر كثيرا بالأسعار المنافسة. Ln Quk = 54.1 - 1.00 Ln $P_{\text {eg }}+0.8$ Ln $P_{\text {India }}$

$$
(4.5)^{\star \star}(-2.5)^{\star \star} \quad(3.8)^{\star \star}
$$

+0.08 Ln $P_{\text {eg fresh }} \quad+11.2$ Ln Popuk

(0.58)

$(3.3)^{\star *}$

$R^{2}=0.80 \quad$ Adj. $R^{2}=0.74 \quad F=12.03^{\star *}$

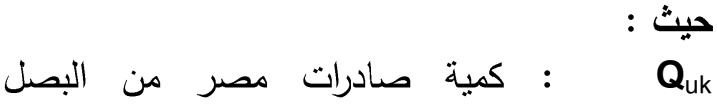
المجفف لسوق المملكة المتحدة بالطن.

: $\quad \mathbf{P}_{\text {eg }}$ المجفف لسوق المملكة المتحدة لئرة

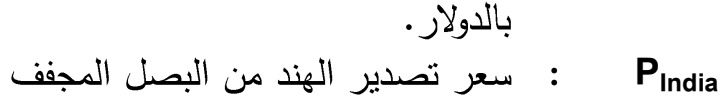
لسوق المملكة المتحدة بالدولار.

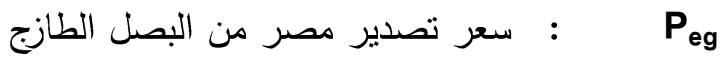

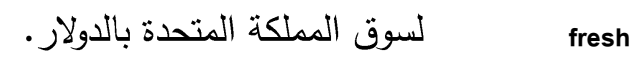
Popuk

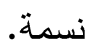

فى حين زيادة كل من سعر تصدير البصل المجفف المصرى بنسبة 1\% يترتب عليه تناقص كمية صادرات مصر من البصل المجفف للسوق البلجيكى

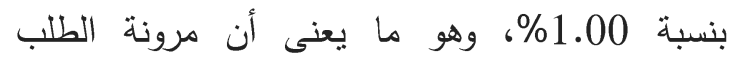
السعرية على البصل المصرى المجفف وإن كانت سالبة الميل ومنطقيه من وجهة النظر الإقتصادية إلا إنها تساوى الواحد ومن ثم فهى مرونه متكافئه أى أن التغير التهي

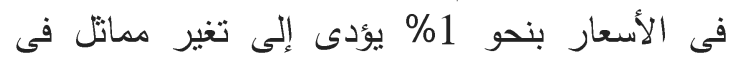
الإتجاه العكسى للكمية المطلوبه.

حيث ثبتت المعنوية الإحصائية عند مستوى 0.05

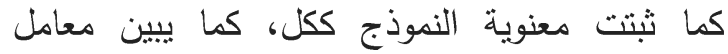
التحديد المعدل أن حوالى 74\% من التنغيرات الحاثة

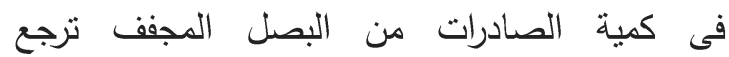
للمتغيرات المستقلة محل الدراسة. 
أما بالنسبة لمرونة الطلب العبورية يلاحظ أن سعر

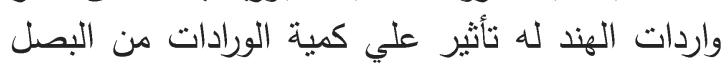

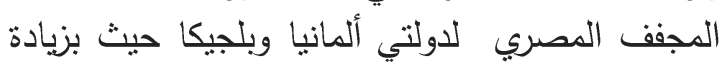

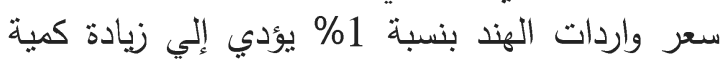

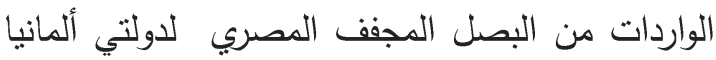

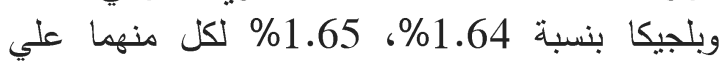
الترتيب، بينما يتضح من جدول (3) ايضا أن سعر لئه

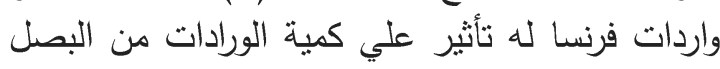

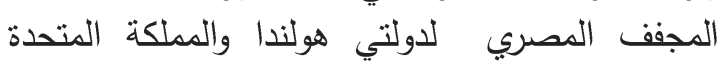

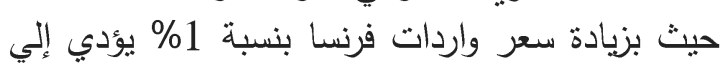

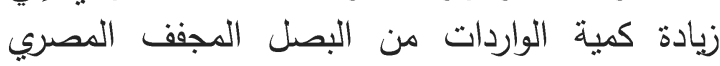

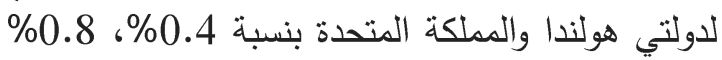
لكل منهما علي الترتيب.

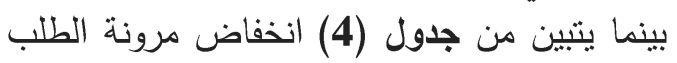

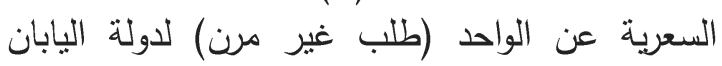

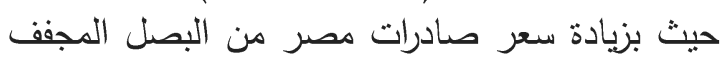
لليابان بنسبة 1\% بؤئدي إلي انخفاض كمية الصادرات بنسبة 0.51\%، بينما كانت مرونة البئة الطفاض كلبة السعرية

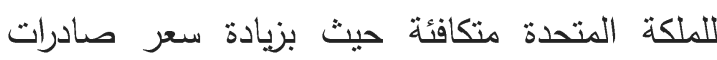

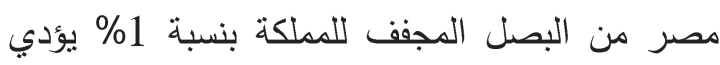

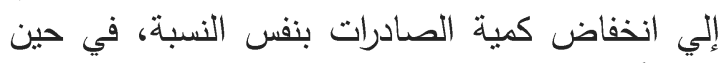

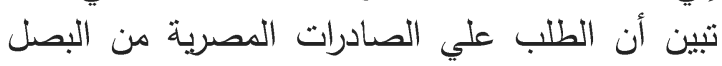
المجفف مرن بالنسبة لدول هولندا - البرازيل - بلجيكا

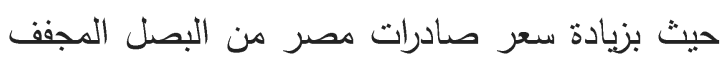

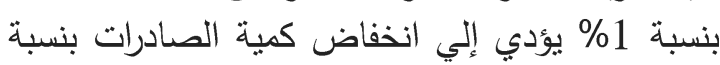

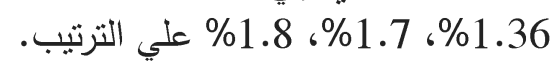
بينما يتضح من مرونة الطلب الاخلية بزيادة دخل

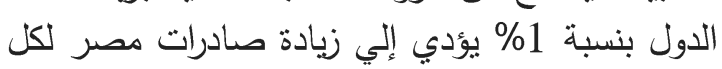

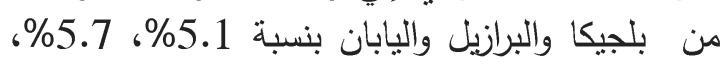
6.4 علي الترتيب. أما بالنسبة لمرونة الطلب العبورية للبية للبصل الطازج

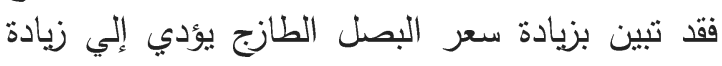

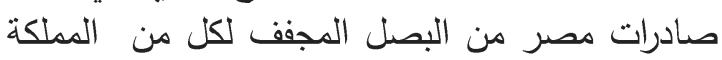

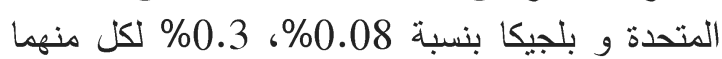

$$
\text { علي الترتيب. }
$$

\section{مما سبق يمكن التأكيا على النتائج التالية}

يثير جدول (3) إلى انخفاض مرونة الطلب

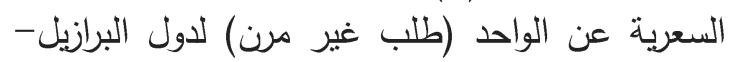

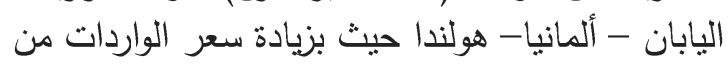

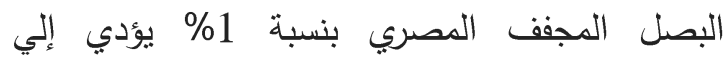

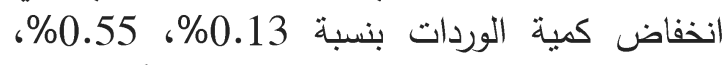

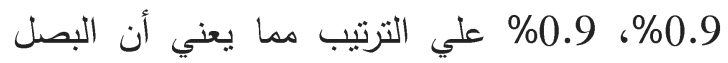
المصري المجفف لتلأك الدول له أهمية كبيرة بحيث أن أن أن

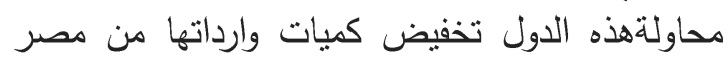

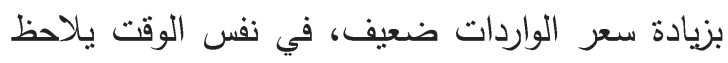

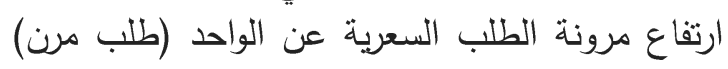

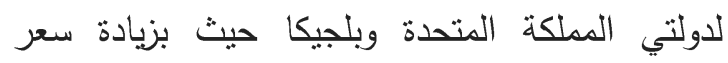

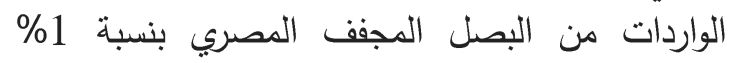

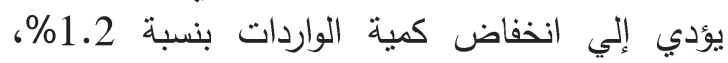

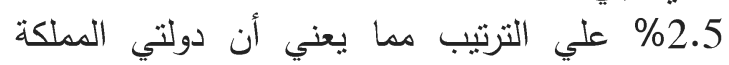

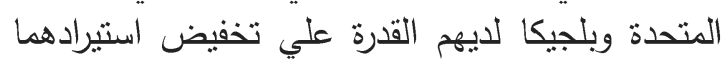

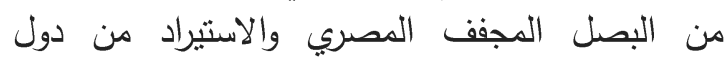

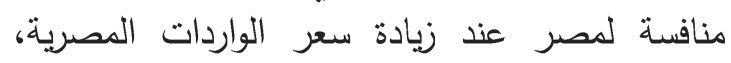

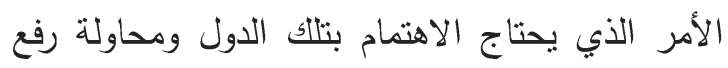

$$
\text { النصيب السوقي المصري لديهما. الأيما }
$$

جدول 3. درونات الطلب السعرية والعبورية والاخلية في واردات الأسواق الرئيسة المستوردة للبصل المبل المصرية ولاتية

\begin{tabular}{|c|c|c|c|c|}
\hline \multicolumn{2}{|c|}{ المرونة العبورية } & المخلية & المعروية & الدولة \\
\hline USA 1.65 & India1.64 & - & -0.9 & ألمانيا \\
\hline - & France 0.4 & - & -0.9 & هولندا \\
\hline - & - & 4.3 & -0.55 & الثابان \\
\hline 1.1 & India1.65 & - & -2.5 & بلجيكا \\
\hline - & France 0.8 & - & $\begin{array}{l}-1.2 \\
-0.13\end{array}$ & المتحدة \\
\hline & 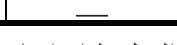 & $=$ & -0.13 & أبرازيل \\
\hline
\end{tabular}
المجفف 


$$
\text { محددات الطلب العالمى علي البصل المجفف المصري }
$$

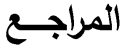

أولاً: المراجع العربية

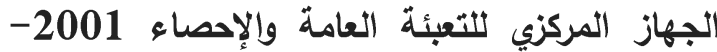

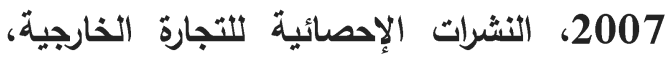

أعدد متفرقة، 20012017 2017.

جابر أحمد بسيونى، 2003.

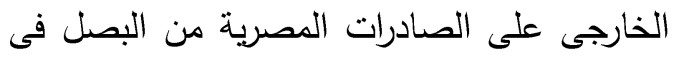

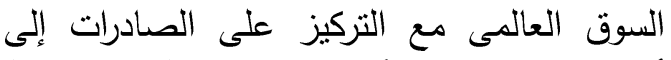

أسواق الاتحاد الأوروبى، المجلة المبل المصرية

للإقتصاد الزراعى، المجلد الثالث عشر، العداد الثاد

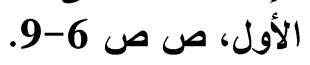

مصطفى عبد الرزلق حاج حميدي، 2015. دراسة

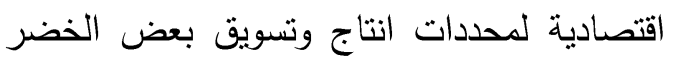

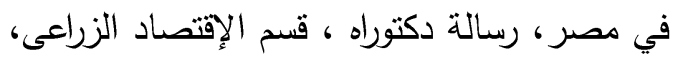

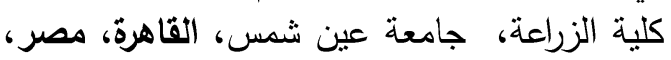

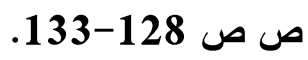

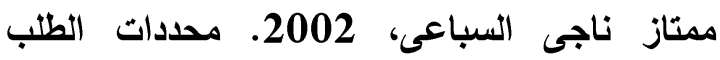

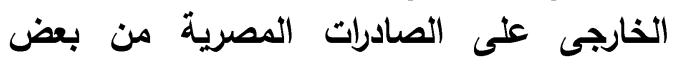

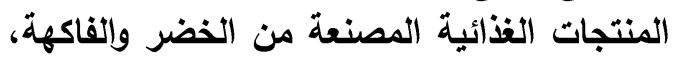

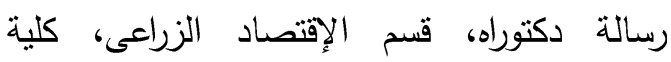

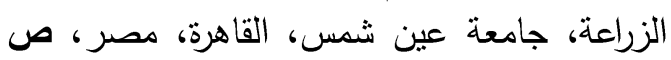

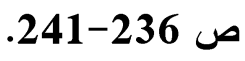

\section{ثانياً: المراجع الأجنبية}

Abdelmaqsoud, A.M., 2007. The demand for Food in the Arab region, Mansoura Journal of Agricultural Sciences, pp. 926-936.

Eshry, M.Kh., 2002. Comparative and Competitive advantages of Egyptian vegetables in the world markets, Ph.D. Thesis, Faculty of Agriculture, Ain Shams University, Cairo, Egypt, pp. 3-7.
جدول 4. مرونات الطلب السعرية والعبورية والدخلية

\begin{tabular}{|c|c|c|c|c|c|}
\hline \multicolumn{3}{|c|}{ المرونـة العبورية } & المرونة & المرونة & الدولة \\
\hline - & - & - & - & -1.36 & هولندا \\
\hline 一 & - & - & 6.4 & -0.51 & اليابان \\
\hline 0.45 & 1.01 & 0.3 & 1 & -18 & \\
\hline Spain & France & Fresh & & & \\
\hline & 0.8 & 0.08 & & , & المملكة \\
\hline - & India & Fresh & - & & المتحدة \\
\hline - & - & - & 5.7 & -1.7 & البرازيل \\
\hline
\end{tabular}

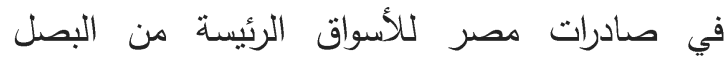
المصري المجفف

المصدر: نتائج معادلات دوال طلب الدول على صادرات البصل

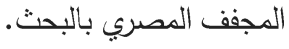

يتضح من مقارنة نتائج جدول (3) بنتائج

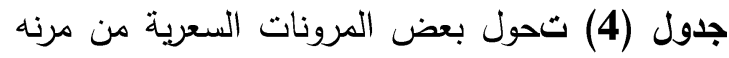

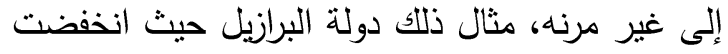

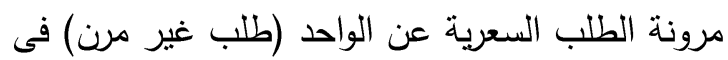
حالة استخدام أحصاءات الواردات بينما تحولت المرات المرونة

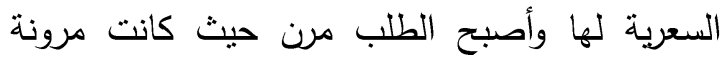
الطلب السعرية أكبر من الواحد فى حالة استخدام

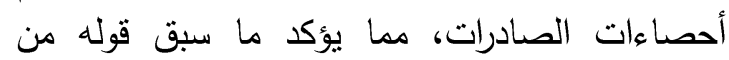

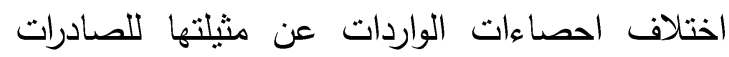

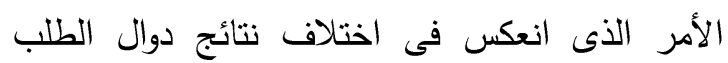

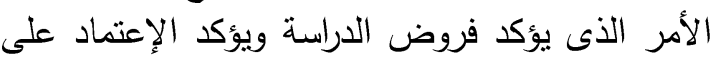
بيانات الواردات بالارجة الأولى. 